\title{
Impacts of Oceanic Preexisting Conditions on Predictions of Typhoon Hai-Tang in 2005
}

\author{
Akiyoshi Wada and Norihisa Usui \\ Meteorological Research Institute, 1-1 Nagamine, Tsukuba, Ibaraki 305-0052, Japan \\ Correspondence should be addressed to Akiyoshi Wada, awada@mri-jma.go.jp \\ Received 31 December 2009; Revised 13 April 2010; Accepted 27 May 2010 \\ Academic Editor: Zhaoxia Pu
}

Copyright (๑) 2010 A. Wada and N. Usui. This is an open access article distributed under the Creative Commons Attribution License, which permits unrestricted use, distribution, and reproduction in any medium, provided the original work is properly cited.

\begin{abstract}
We investigated the impact of variations in oceanic preexisting conditions on predictions of Typhoon Hai-Tang (2005) by using a coupled atmosphere-ocean model with $6-\mathrm{km}$ horizontal resolution and providing the oceanic initial conditions on 12 July from 1997 to 2005 to the model. Variations in oceanic preexisting conditions caused variation in predicted central pressure of nearly $18 \mathrm{hPa}$ at $72 \mathrm{~h}$, whereas sea-surface cooling (SSC) induced by Hai-Tang caused a predicted central pressure difference of about $40 \mathrm{hPa}$. Warm-core oceanic eddies up to a few hundred kilometers across and a deep mixed layer climatologically distributed in the western North Pacific led to high mixed-layer heat potential, which increased latent heat flux, water vapor, and liquid water contents around Hai-Tang's center. These increases were closely associated with Hai-Tang's intensification. SSC negatively affected the eyewall, whereas variations in oceanic preexisting conditions remarkably affected spiral rainbands and the magnitude of SSC.
\end{abstract}

\section{Introduction}

Advances in ocean data assimilation systems have enabled us to further understand tropical cyclone (TC) activity and the ocean response at weather-forecasting as well as seasonal to climate time scales. The relationships between TC activity and variations in the global ocean are of growing interest on seasonal to climate time scales. In contrast, TC-induced sea-surface cooling (SSC), the decrease in seasurface temperature (SST) during and after the passage of a TC in general, is a well-known ocean response to a TC on a weather-forecasting scale. Previous studies reported that SSC varied depending on oceanic preexisting conditions [1] as well as on TC intensity and translation speed [2]. However, the dynamic and thermodynamic processes associated with SSC remain controversial $[1,3,4]$ although vertical turbulent mixing and upwelling are known to be important [2]. According to our current understanding of the relationship between TC activity and ocean thermal forcing, not only SST but also temperature and salinity profiles in the upper ocean are important for determining TC intensity, whereas SSC slightly affects TC track prediction [5].
TC heat potential (TCHP), a measure of the oceanic heat content from the surface to the $26^{\circ} \mathrm{C}$ isotherm depth (Z26), is highly correlated with TC intensity in the western North Pacific (WNP) on seasonal to climate time scales $[6,7]$. TCs tend to rapidly intensify in the WNP when they pass over a region with a high TCHP and a deep Z26. Providing accurate oceanic preexisting conditions as oceanic initial conditions to a coupled atmosphere-ocean model used for typhoon prediction is thus important if the model is to predict TCs precisely, particularly their intensity, but how oceanic preexisting conditions affect TC predictions is still unclear.

On a weather-forecasting scale, idealized numerical experiments have demonstrated that TC-induced SSC substantially affects TC intensity during its intensification phase but not during its mature phase [8]. Rapid TC intensification during its intensification phase is caused by mesovortices, filamentation, and vortex Rossby waves enhanced by TCscale cyclonic circulation. SSC in Wada [8], defined as a decrease in computed SST from the initial SST, plays a role in weakening mesovortices, which suppresses lowertropospheric cooling by evaporation along spiral rainbands 
and the associated local anticyclonic flow around the mesovortices. The resulting relatively high central pressure then weakens the TC-scale cyclonic circulation. This negative feedback [9] reduces TC intensification.

The purpose of the present study was to quantitatively evaluate the impact of oceanic preexisting conditions on predictions of a TC during its intensification phase on a weather-forecasting time scale. We performed several numerical prediction experiments for Typhoon Hai-Tang (2005) by providing nine different oceanic initial conditions to a coupled atmosphere-ocean model. The initial conditions were determined from daily oceanic reanalysis data for 1997 to 2005 calculated by the North Pacific version of the Meteorological Research Institute (MRI) ocean variational estimation (MOVE) system [10].

This paper consists of five sections. Section 2 describes the model and the experiment design. Section 3 describes the results of numerical prediction experiments. Section 4 discusses the role of variation in oceanic preexisting conditions on predictions of TC intensity and the sensitivity of predictions of Hai-Tang's intensity to upper-ocean variations on seasonal to climate time scales. Section 5 is the conclusion.

\section{Model and Experiment Design}

This section consists of four subsections. Section 2.1 explains the best-track data used in this study. Section 2.2 presents a summary of each component of the coupled atmosphereocean model. Section 2.3 outlines the experiment design. Section 2.4 defines mixed-layer heat potential.

2.1. Best-Track Data. To validate the results of the numerical prediction experiments described below, the best-track data of Hai-Tang's positions and central pressures, archived by the Regional Specialized Meteorological Center [6], were used. Best-track data are defined as the sustained 10-min means. We used predicted central pressure to represent Hai-Tang's predicted intensity.

2.2. Coupled Model. The nonhydrostatic atmosphere model coupled with the ocean model (NCM) consists of a nonhydrostatic atmosphere model (NHM) [11] and a mixedlayer ocean model $[2,8]$. An oceanic sublayer scheme for calculating an increase in temperature in the upper-ocean skin layer [12] is included in the mixed-layer ocean model for calculating diurnally varying SST.

2.2.1. NHM. The NHM used in the present study is an older version of the nonhydrostatic mesoscale model developed for operational use at the Japan Meteorological Agency in collaboration with the MRI. Physical schemes incorporated into the NHM and NCM are an explicit three-ice bulk microphysics scheme [13] in conjunction with the KainFritsch convective parameterization scheme [14], a resistance law assumed for sensible and latent heat fluxes and wind stress in the surface boundary layer; exchange coefficients for sensible and latent heat fluxes and wind stress over the sea, determined using Kondo's [15] bulk formulas, a turbulent closure model in the atmospheric-boundary layer $[16,17]$, and an atmospheric radiation scheme [18].

2.2.2. Mixed-Layer Ocean Model. The mixed-layer ocean model is a reduced gravity model developed at the MRI $[2,8]$. In the present study, the ocean model consists of three layers and four levels. The uppermost layer is a mixed layer with vertically uniform density. The middle layer is a seasonal thermocline and shows the largest vertical temperature gradient among the three layers. The bottom layer is assumed to be undisturbed by entrainment. Four levels consist of the surface, the base of the mixed layer/top of the thermocline, the base of the thermocline/top of the bottom layer, and the sea floor. Temperature and salinity are calculated only at the surface and at the base of the mixed layer, whereas layer thickness and oceanic flows are calculated for all layers. The water depth is limited to $2000 \mathrm{~m}$. The mixed-layer depth is determined from oceanic reanalysis data by assuming a difference in density from the surface of no more than $0.25 \mathrm{~g} \mathrm{~m}^{-3}$ and it is limited to $200 \mathrm{~m}$. The base of the thermocline is limited to $600 \mathrm{~m}$.

2.2.3. Oceanic Sublayer Scheme. The specifications of the mixed-layer ocean model described in Section 2.2.2 are insufficient for realistic simulation of the amplitude of diurnal SST variations because of the thickness $(>1 \mathrm{~m})$ of the mixed layer. To improve the simulation of diurnally varying SST, we incorporated into the mixed-layer ocean model an oceanic sublayer scheme that we developed following Schiller and Godfrey [19], but with short-wave absorption/penetration calculated using the formulation of Ohlmann and Siegel [20].

According to the algorithm of Schiller and Godfrey's [19] scheme, a skin layer forms in the uppermost layer when short-wave radiation warms the sea surface. The thickness of the skin layer is determined from the total amount of shortwave radiation and the cumulative wind stress from sunrise to sunrise. Short-wave radiation and wind stress are provided by the NHM to the mixed-layer ocean model at every time step, but short-wave radiation and wind stress accumulate between sunrises only in the oceanic sublayer scheme. The thinner the skin layer is, the larger the amplitude of diurnal SST variation becomes. After sunset, the skin layer vanishes and its depth is reset to the reference depth $(5 \mathrm{~m}$ in the present study). The total amounts of short-wave radiation and wind stress then remain constant within the oceanic sublayer scheme until next sunrise.

Ohlmann and Siegel [20] derived the formulas associated with short-wave absorption/penetration by multiple regression analysis. Short-wave absorption/penetration is a function of the chlorophyll-a concentration $\left(\mathrm{mg} \mathrm{m}^{-3}\right)$, the cloud index under cloudy conditions, and the solar zenith angle under clear-sky conditions. When the chlorophylla concentration is high, the amplitude of diurnal SST variations tends to be large [12].

2.3. Experiment Design. NHM and the mixed-layer ocean model each contain $721 \times 421$ horizontal grids and the 
horizontal grid spacing is $6 \mathrm{~km}$. NHM has 40 vertical levels, and the interval between levels varies from $40 \mathrm{~m}$ near the surface to $1180 \mathrm{~m}$ for the uppermost layer. The top height is nearly $23 \mathrm{~km}$. The time step of the NHM is $12 \mathrm{~s}$, and that of the mixed-layer ocean model is $72 \mathrm{~s}$. Atmospheric and oceanic data are exchanged between the NHM and mixedlayer ocean model every $72 \mathrm{~s}$ as follows: the SST calculated in the mixed-layer ocean model is provided to the NHM as the surface boundary condition, and wind stress, short-wave and long-wave radiation, sensible and latent heat fluxes, and precipitation accumulated by the NHM during the time step of the ocean model $(72 \mathrm{~s})$ are provided to the mixed-layer ocean model as atmospheric forcing data.

To set the initial and boundary atmospheric conditions for the NHM and NCM, we first ran hydrostatic global spectral model (GSM) version T213L40 for $72 \mathrm{~h}$. The horizontal resolution of GSM T213L40 is nearly $60 \mathrm{~km}$. To avoid gaps in the horizontal resolution of downscale calculations, we next ran a hydrostatic regional spectral typhoon model (TYM) with a horizontal grid spacing of nearly $20 \mathrm{~km}$ at Hai-Tang's initial position for $72 \mathrm{~h}$. The TYM provided initial and boundary atmospheric conditions every $3 \mathrm{~h}$ based on the output of the GSM [5] to both the NHM and NCM. It should be noted that a bogus typhoon was incorporated only into the numerical prediction by the TYM, and that the effect of the bogus typhoon must be considered in the numerical prediction experiments of the NHM and NCM, because the initial atmospheric conditions for the NHM and NCM runs were based on the output of the TYM. Lateral boundary conditions created from the TYM output were also provided to NHM and NCM every $3 \mathrm{~h}$. The integration time of GSM, TYM, NHM, and NCM was $72 \mathrm{~h}$, starting from 1200 UTC 12 July 2005.

Oceanic initial conditions were obtained from daily oceanic reanalysis data with a horizontal grid spacing of $0.5^{\circ}$ from 1997 to 2005 . Daily oceanic reanalysis data were calculated by the MOVE system [10]. Table 1 lists the numerical prediction experiments conducted in the present study. We ran nine experiments with the NCM and another nine experiments with the NHM, not being coupled with the mixed-layer ocean model.

To investigate the impact of variations in oceanic preexisting conditions on predictions of Hai-Tang, nine separate sets of oceanic initial conditions were created from the daily oceanic reanalysis data of 12 July during 1997-2005 (Table 1). The nine oceanic initial conditions include some remarkable oceanic variations at seasonal to climate time scales: for example, 12 July 1999 was during a mature La Niña event, whereas 12 July 2002 was during a mature El Niño event; 12 July 2005 fell at the end of a central Pacific warming event during the transition to La Niña.

Hai-Tang was a super-typhoon, defined as a typhoon with maximum sustained 1-min-mean surface winds of $67 \mathrm{~m} \mathrm{~s}^{-1}$ or greater. According to the best-track data, HaiTang formed near $22.9^{\circ} \mathrm{N}, 149.2^{\circ} \mathrm{E}$ at $0000 \mathrm{UTC}$ on 13 July 2005. Hai-Tang initially moved northwestward; then, after it entered the tropical cyclogenesis phase, it turned to move southwestward to westward while rapidly intensifying. Hai-Tang attained a central pressure of $920 \mathrm{hPa}$
TABLE 1: Designations of the numerical-prediction experiments, the year used for the oceanic preexisting conditions, and the model, NCM and NHM, used to conduct the experiments. El Niño years are followed by (E) and La Niña years by (L).

\begin{tabular}{lcc}
\hline Experiment & Year & Model \\
\hline NCM97 & $1997(\mathrm{E})$ & NCM \\
NCM98 & 1998 & NCM \\
NCM99 & $1999(\mathrm{~L})$ & NCM \\
NCM00 & 2000 & NCM \\
NCM01 & 2001 & NCM \\
NCM02 & $2002(\mathrm{E})$ & NCM \\
NCM03 & 2003 & NCM \\
NCM04 & 2004 & NCM \\
NCM05 & 2005 & NCM \\
NHM97 & $1997(E)$ & NHM \\
NHM98 & 1998 & NHM \\
NHM99 & $1999(\mathrm{~L})$ & NHM \\
NHM00 & 2000 & NHM \\
NHM01 & 2001 & NHM \\
NHM02 & $2002(E)$ & NHM \\
NHM03 & 2003 & NHM \\
NHM04 & 2004 & NHM \\
NHM05 & 2005 & NHM \\
\hline
\end{tabular}

at 0600 UTC on 16 July. This study investigated HaiTang's rapid-intensification phase, starting with the tropical cyclogenesis phase. Therefore, we set the initial integration time to 1200 UTC on 12 July 2005 . We could not, however, reproduce the tropical cyclogenesis phase realistically in the present numerical prediction experiments because the bogus typhoon included in the initial atmospheric conditions negatively affected the prediction of Hai-Tang's track, as described in Section 3.1. Therefore, we focused on the impact of variations in the oceanic preexisting conditions on predictions of Hai-Tang's rapid intensification.

Hai-Tang passed over two warm-core eddies, characterized by a high sea-surface height (SSH) with a positive SSH anomaly (SSHA), a high TCHP, and a deep Z26, in the WNP as it rapidly intensified (Figure 1). Conversely, as it passed over the cold wake, it ceased to intensify and its best-track central pressure remained constant (Figure 1(a)). The warm-core eddy at around $22^{\circ} \mathrm{N}, 148^{\circ} \mathrm{E}$ (Figure 1(b)), where the SSH was high, was a few hundred kilometers across. The MOVE system reproduced this warm-core eddy (W1, Figure 1(c)) reasonably well, as well as the high SSH associated with the other warm-core eddy (W2, Figures 1(a) and $1(\mathrm{c})$ ). Hai-Tang's intensification was thus associated with these warm-core eddies.

2.4. Mixed-Layer Heat Potential. Here, we defined the mixedlayer heat potential (MLHP: $\mathrm{kJ} \mathrm{cm}^{-2}$ ) [8] as

$$
Q_{\mathrm{MLHP}}=\rho C_{p}\left(T_{1}-26\right) h_{1},
$$

where $\rho$ is the density of sea water in the mixed layer underneath a TC, which is assumed to be constant; $C_{p}$ is the 


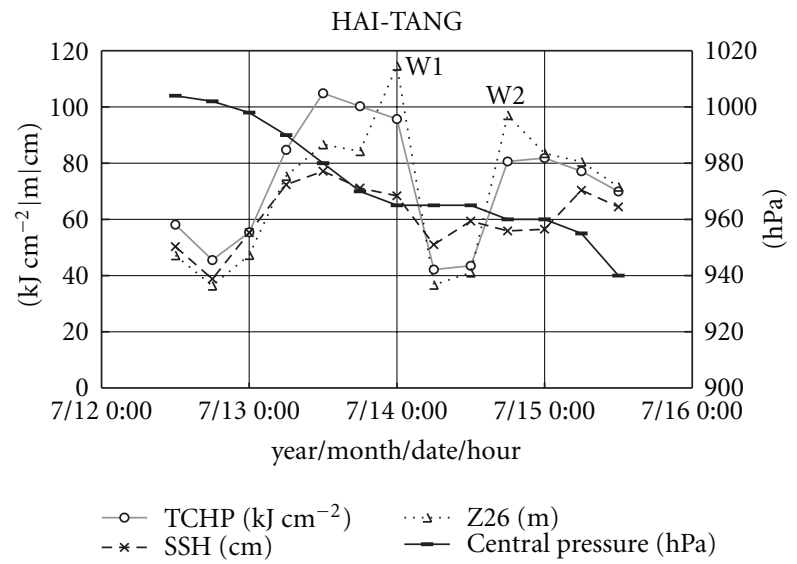

(a)

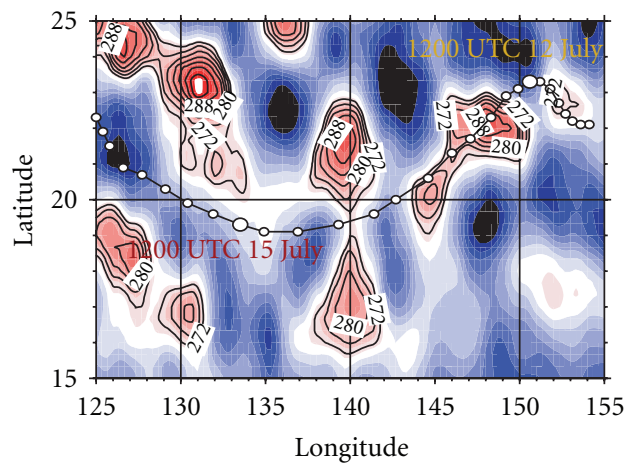

(b)

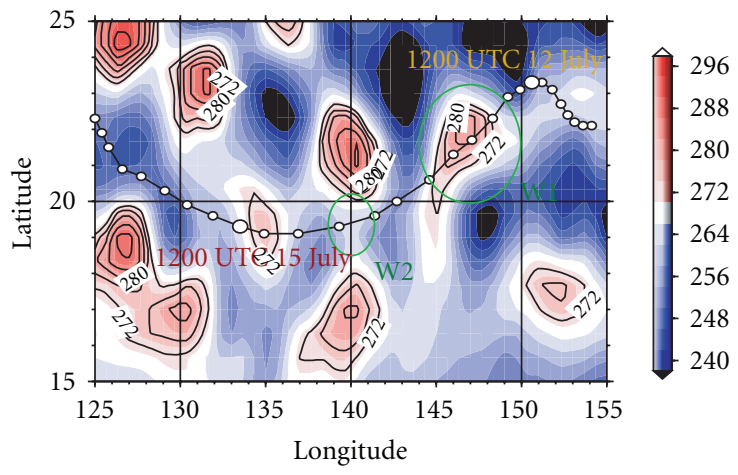

(c)

Figure 1: (a) Time series of best-track central pressure, tropical-cyclone heat potential (TCHP), 26 ${ }^{\circ} \mathrm{C}$ isotherm depth (Z26), and sea surface height (SSH) from 1200 UTC 12 July to 1200 UTC 15 July 2005. (b) Horizontal distribution of the 7-day mean SSH (cm) obtained from the Archiving and Validating Interpretation of Satellite Oceanographic (AVISO) data product (ftp://ftp.aviso.oceanobs .com/pub/oceano/AVISO/SSH/duacs/global/dt/ref/madt/merged/h/) for 13 July 2005. (c) Horizontal distribution of daily SSH (cm) calculated by the MOVE system and corrected to make the 7-day spatial mean of the daily MOVE SSH equal to that of the AVISO SSH. W1 and W2 in part (a) and the green circles in part (c) indicate the warm-core eddies. The large circles along Hai-Tang's track in parts (b) and (c) indicate the start and end positions of the numerical integration.

specific heat at constant pressure; $T_{1}$ is the SST underneath a TC; $h_{1}$ is the mixed-layer depth (MLD) underneath a TC. The variables $\rho, T_{1}$, and $h_{1}$ were obtained from daily oceanic reanalysis data.

\subsection{Tropical-Cyclone Heat Potential. TCHP $\left(\mathrm{kJ} \mathrm{cm}^{-2}\right)$ is defined as}

$$
Q_{\mathrm{TCHP}}=\sum_{z=0}^{H} \rho_{h} C_{p}\left(T_{h}-26 .\right) \Delta Z_{h} \text {, }
$$

where $\rho_{h}$ is the density of the sea water at each layer, $T_{h}$ is the sea temperature $\left({ }^{\circ} \mathrm{C}\right)$ at each layer, $\Delta Z_{h}$ is the thickness at each layer, $H$ is the vertical level of depth corresponding to Z26, and $h$ is the variable number of vertical levels based on the configuration of the ocean data reanalysis system described in Section 3. When $T_{h}$ is below $26^{\circ} \mathrm{C}$, TCHP at the layer is assumed to be zero.

\section{Results}

3.1. Track and Intensity Prediction. We first investigated the impact of variations in oceanic preexisting conditions on predictions of Hai-Tang's track. Figure 2 depicts Hai-Tang's best-track positions and the mean positions predicted by NHM and NCM (Table 1). Both predicted tracks show a marked northwestward bias during the early integration period, and they both subsequently turn southwestward. Thus, the track predictions did not significantly differ between NHM and NCM. At $72 \mathrm{~h}$, the predicted tracks approach Hai-Tang's best-track position. Table 2 lists the mean predicted positions for every $24 \mathrm{~h}$ and their standard deviations. The maximum standard deviation at $72 \mathrm{~h}, 0.27^{\circ}$ of longitude, is comparable to the difference of center position at $72 \mathrm{~h}$ between NHM and NCM, nearly $0.3^{\circ}$ of latitude (Table 2). Thus, variations in oceanic preexisting conditions had no significant impact on predictions of HaiTang's track as well as a difference in predicted SSTs between NHM and NCM. 
TABLe 2: Mean longitude and latitude and standard deviations of the predicted position every $24 \mathrm{~h}$ and best-track longitude and latitude.

\begin{tabular}{|c|c|c|c|c|c|c|c|}
\hline Experiment & & $\operatorname{lon}(24 \mathrm{~h})$ & lat $(24 \mathrm{~h})$ & $\operatorname{lon}(48 \mathrm{~h})$ & lat(48h) & $\operatorname{lon}(72 \mathrm{~h})$ & lat $(72 \mathrm{~h})$ \\
\hline \multirow[t]{2}{*}{ NHM } & $\operatorname{MEAN}\left({ }^{\circ}\right)$ & 145.21 & 22.51 & 139.49 & 19.83 & 133.42 & 18.72 \\
\hline & $\operatorname{STD}\left(^{\circ}\right)$ & 0.05 & 0.08 & 0.14 & 0.09 & 0.26 & 0.12 \\
\hline \multirow[t]{2}{*}{$\mathrm{NCM}$} & $\operatorname{MEAN}\left({ }^{\circ}\right)$ & 145.27 & 22.61 & 139.67 & 19.86 & 133.69 & 19.02 \\
\hline & $\operatorname{STD}\left(^{\circ}\right)$ & 0.04 & 0.11 & 0.10 & 0.08 & 0.27 & 0.20 \\
\hline Best track & $\left({ }^{\circ}\right)$ & 147.1 & 21.7 & 141.4 & 19.6 & 133.5 & 19.3 \\
\hline
\end{tabular}

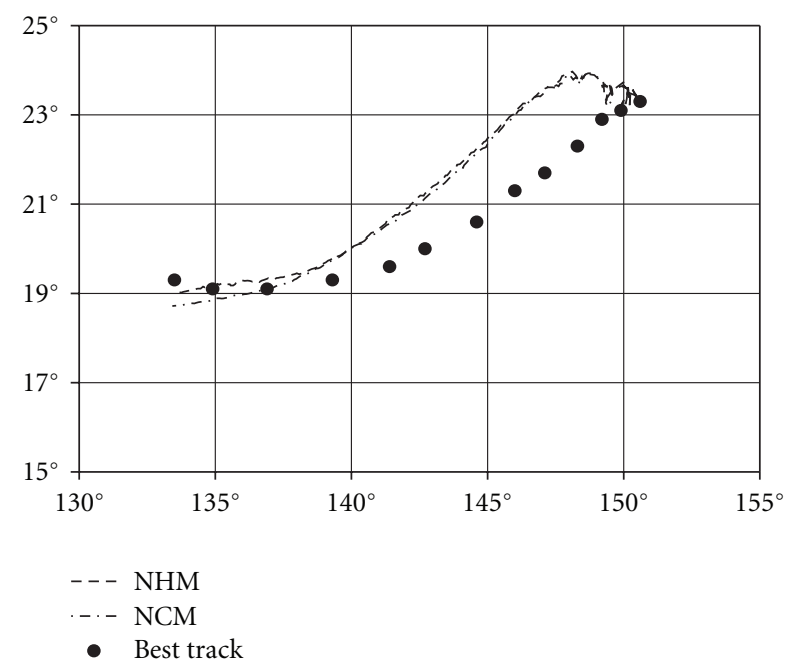

FIGURE 2: Hai-Tang's best-track positions from 1200 UTC 12 July $\left(23.3^{\circ} \mathrm{N}, 150.6^{\circ} \mathrm{E}\right)$ to $1200 \mathrm{UTC} 15$ July $2005\left(19.3^{\circ} \mathrm{N}, 133.5^{\circ} \mathrm{E}\right)$ and the mean predicted positions of the nine NHM and nine NCM experiments. Longitude is shown on the horizontal axis and latitude on the vertical axis.

The impact of SSC on predictions of TC central pressure was remarkable, particularly during the later period of numerical integration [5]. We investigated the evolution of the central pressures predicted by NCM (Figure 3(a)) and NHM (Figure 3(b)) along with their mean difference and standard deviations (Figure 3(c)). All of the central pressures predicted by NCM were higher than the best-track central pressure after $18 \mathrm{~h}$ (Figure 3(a)), whereas most central pressures predicted by NHM were lower (Figure 3(b)). The difference in predicted central pressure between NHM and NCM became significant after $24 \mathrm{~h}$ and small after $48 \mathrm{~h}$ (Figure 3(c)). The twofold standard deviation of the predicted central pressure difference was nearly $18 \mathrm{hPa}$ at $72 \mathrm{~h}$ (Figure 3(c)). This value represents the amplitude of the variation in the predicted central pressure due to the variation in oceanic preexisting conditions. The amplitude of $18 \mathrm{hPa}$ is less than the difference in predicted central pressure between NHM and NCM, which increased to more than $40 \mathrm{hPa}$ at $72 \mathrm{~h}$, suggesting that the impact of oceanic preexisting conditions on predictions of Hai-Tang's intensity was smaller than the impact of the difference between NHM and NCM in the SST decrease caused by Hai-Tang's passage.
3.2. Oceanic Responses. We defined SST as temperature at the first level of the mixed-layer model plus skin temperature calculated in the oceanic sublayer scheme and SSC as the decrease in predicted SST from the initial SST due to Hai-Tang's passage hereafter. It should be noted that the initial SST does not change during the integration in the experiments by NHM. Therefore, the magnitude of SSC at a certain integration time was equal to the difference in SST at a certain integration time between NHM and NCM. We investigated the evolution of mean SST and SSC underneath Hai-Tang and their standard deviations to determine the impact of the variations in oceanic preexisting conditions on SSC (Figure 4). Mean SST was calculated as the average SST underneath Hai-Tang's center position among the nine predictions by NCM. Each SSC value was calculated as the difference in predicted SST underneath Hai-Tang's center position from the initial SST. Mean differences in both SST and SSC were calculated as the averaged differences between NHM and NCM in the predictions of the nine experiments. The minimum mean SST and the maximum mean decrease in SST became significant at around $18 \mathrm{~h}$, when the difference in the predicted central pressures between NHM and NCM also became apparent. The twofold standard deviation associated with the variations in SST underneath Hai-Tang was nearly $0.7^{\circ} \mathrm{C}$, and the standard deviation associated with the variations in SSC was nearly $0.5^{\circ} \mathrm{C}$. The standard deviation was large from the initial time to $18 \mathrm{~h}$ as predicted Hai-Tang rapidly intensified. After $18 \mathrm{~h}$, the rate of intensification decreased and SST underneath Hai-Tang began to increase; however, it remained lower than the initial SST underneath Hai-Tang even though it did not decrease monotonically during the passage. The trend of predicted SST underneath Hai-Tang obtained here differed from the result of an idealized numerical experiment [8] because SSC was sensitive to the variations in the oceanic preexisting conditions such as the spatial and temporal variations in the preexisting warm-core eddy.

To investigate the relationships between the preexisting warm-core eddies and the climatologically deep mixed layer and Hai-Tang's intensification, we calculated MLHP underneath Hai-Tang every hour using (1) and investigated the evolution of mean central pressure and mean MLHP averaged over the nine NCM predictions and their standard deviations (Figure 5). Mean MLHP was calculated as the average in a $1^{\circ}$ grid box at Hai-Tang's center. The trend of mean central pressure was negatively correlated with the trend of mean MLHP, implying that high MLHP underneath Hai-Tang was associated with Hai-Tang's intensification. 

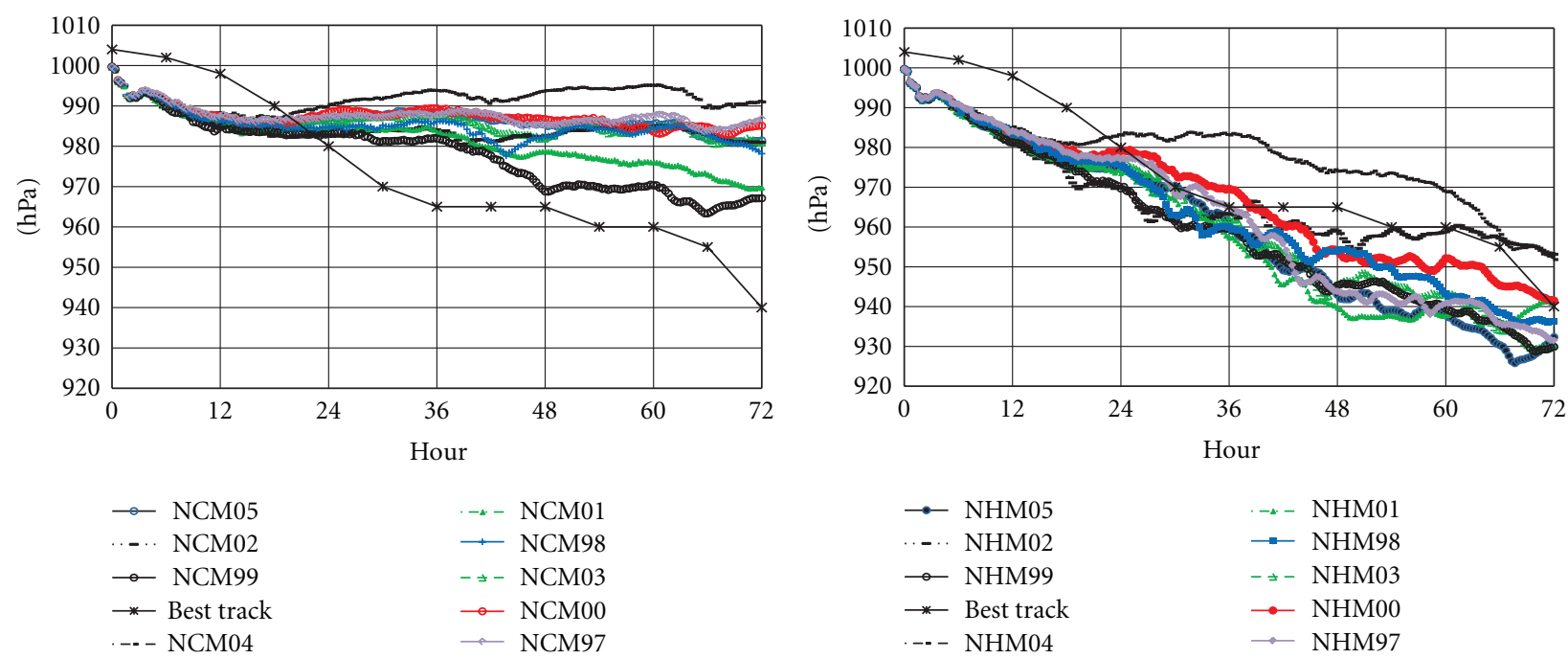

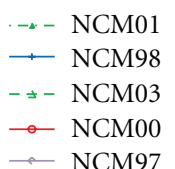

(a)

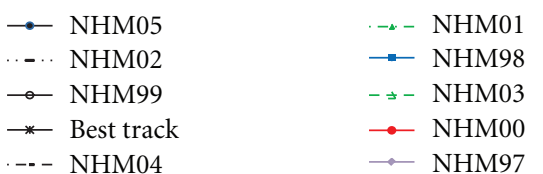

(b)

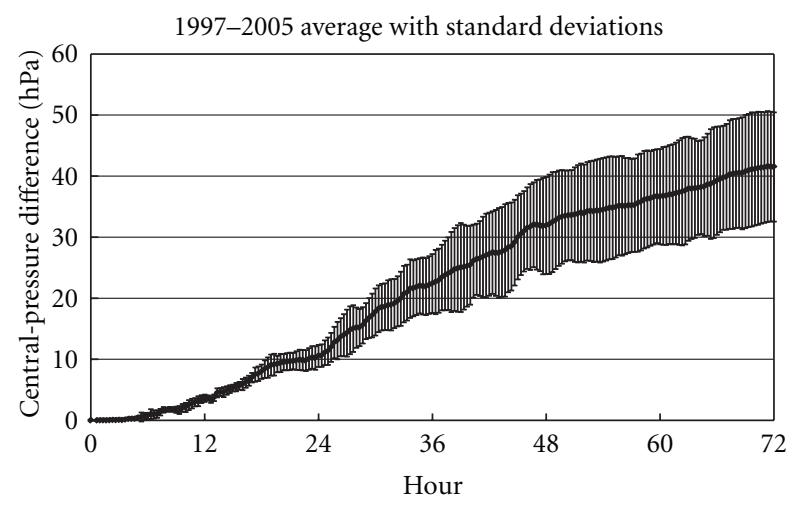

(c)

Figure 3: Time series of best-track central pressures $(\mathrm{hPa})$ and central pressures predicted in each of the nine experiments by (a) NCM and (b) NHM. (c) Time series of the mean differences in central pressure between NCM and NHM values averaged over the nine experiments and their standard deviations.

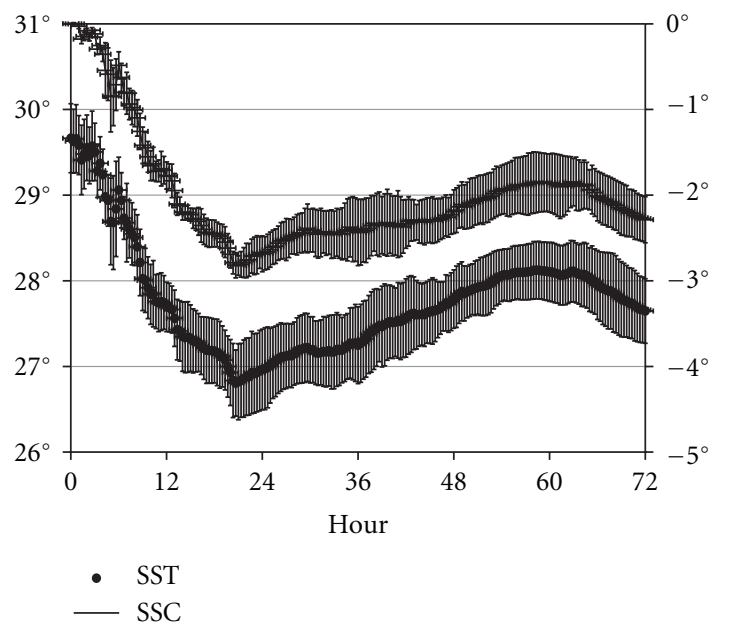

Figure 4: Time series of the mean differences in SST ( ${ }^{\circ} \mathrm{C}$; left axis) and SSC ( ${ }^{\circ} \mathrm{C}$; right axis) between NCM and NHM values averaged over the nine experiments and their standard deviations.
However, Hai-Tang's predicted track bypassed the warmcore eddy where MLHP was relatively high. In other words, Hai-Tang passed over a relatively low MLHP area because of the significant northwestward track-prediction error. This track-prediction error led to an intensity-prediction error caused by the predicted passage over an area with different MLHP. This difference in MLHP caused the standard deviation of predicted central pressure to increase (Figure 5) as the integration time progressed.

We have already mentioned in Section 3.1 that the northwestward track-prediction error during the early integration, which was closely related to the bogus typhoon used in the TYM calculation, caused the predicted Hai-Tang to travel where MLHP was relatively low. In contrast, the best-track data indicated that Hai-Tang passed over the warm-core eddy between $12 \mathrm{~h}$ to $36 \mathrm{~h}$ (Figure 1). In fact, NCM and NHM predicted that Hai-Tang would pass over the warm area north of warm-core eddy W1 (Figure 1(c)) between $0 \mathrm{~h}$ and $24 \mathrm{~h}$ (Figure 5). The amplitude of the variations in MLHP (Figure 5) was relatively high compared with that of 


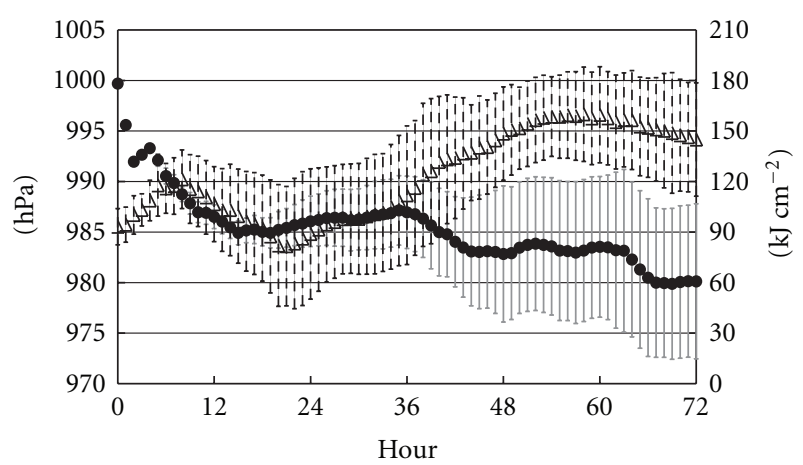

- Mean CP

$\rightarrow$ Mean MLHP

Figure 5: Time series of mean central pressure (CP, left axis) and mean mixed-layer heat potential (MLHP, right axis) predicted by NCM (averages of nine experiments) and their standard deviations.

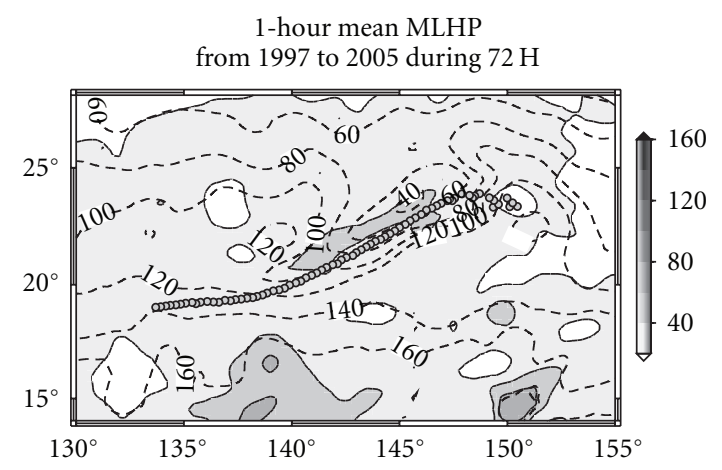

Figure 6: Horizontal distributions of mean MLHP $\left(\mathrm{kJ} \mathrm{cm}^{-2}\right)$ averaged during $72 \mathrm{~h}$ among the nine NCM predictions (contours), and of the standard deviation of MLHP (shading). MLHP values instantaneously calculated every hour were used. Hai-tang's best track is also shown.

the analyzed TCHP variation, even though the high TCHP at 1800 UTC on 14 July (Figure 1) was reproduced by NCM. The overestimation of MLHP caused by the track-prediction error led to prediction of an excessive reintensification of Hai-Tang. This overestimation of MLHP affected Hai-Tang's predicted central pressure continuously, not temporarily during the integration.

The horizontal distribution of mean MLHP averaged over the nine NCM predictions during $72 \mathrm{~h}$ and that of the standard deviation are shown in Figure 6. MLHP was significantly lower on the north side of Hai-Tang's track, where the standard deviation was relatively high, implying that SSC was highly sensitive to variations in oceanic preexisting conditions. The standard deviation was high not only on the north side of Hai-Tang's track but also around $15^{\circ} \mathrm{N}, 138^{\circ} \mathrm{E}$ and $15^{\circ} \mathrm{N}, 150^{\circ} \mathrm{E}$. The high standard deviation in these areas away from Hai-Tang's track can be explained by seasonal to climate time scale variations of oceanic conditions. Figure 6 also indicated that Hai-Tang entered a high-MLHP area during the later integration, and, in fact, the time series of best-track central pressure shows

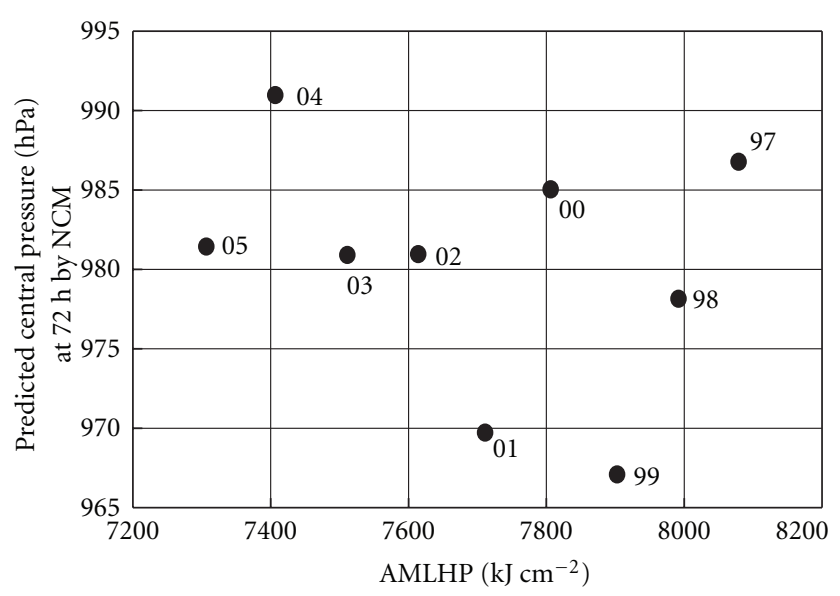

Figure 7: Scatter diagram of central pressure $(\mathrm{hPa})$ versus accumulated MLHP (AMLHP) during $72 \mathrm{~h}\left(\mathrm{~kJ} \mathrm{~cm}^{-2}\right)$ from 1997 to 2005. The numbers by each point indicate which year's daily oceanic reanalysis data on 12 July were used by NCM.

remarkable intensification during this later integration time (Figures 3 and 5).

According to Wada and Usui [6], accumulated TCHP (ATCHP) was highly correlated with the minimum central pressure of TCs occurring from 1998 to 2004. ATCHP is defined as the summation of TCHP within a $1.5^{\circ}$ square around the TC center from the genesis to the phase first reaching the minimum central pressure every six hours, corresponding to the interval of TC best track data. Here, instead of ATCHP, we calculated accumulated MLHP (AMLHP) from the initial time to $72 \mathrm{~h}$. We then investigated the relationship between AMLHP and predicted central pressure at $72 \mathrm{~h}$ among the nine NCM predictions (Figure 7). Interestingly, AMLHP underneath HaiTang decreased monotonically from 1997 to 2005, however, predicted minimum central pressure did not increase monotonically during the period. In particular, predicted minimum central pressure markedly decreased during the strong El Niño Southern Oscillation (ENSO) event from 1997 to 1999. In addition, the predicted minimum central pressure was relatively low in 2005 even though AMLHP was also low. Therefore, a high linear correlation between minimum central pressure and AMLHP cannot be assumed, a result that is not consistent with the findings of Wada and Usui [6]. Thus, whether AMLHP and predicted minimum central pressure are correlated may depend on the oceanic preexisting conditions (Figure 7).

3.3. Atmospheric Impact. The energy source for TC genesis and intensification is moisture provided from the ocean to the atmosphere through latent heat flux. Thus, latent heat flux is an important metric for TC intensification. We investigated the horizontal distribution of the mean latent heat flux averaged over $72 \mathrm{~h}$ among the NCM experiments and that of its standard deviation (Figure 8). Note that the NCM outputs latent heat flux every hour. Mean latent heat flux was relatively small during the early integration 


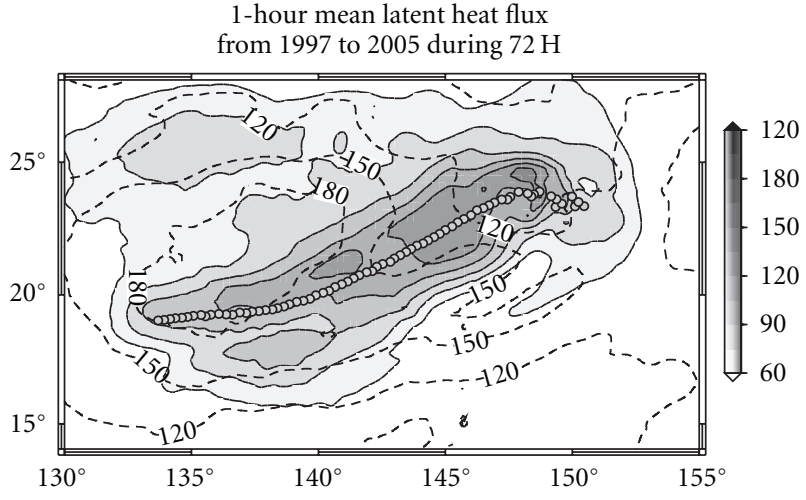

FIGURE 8: Horizontal distributions of mean latent heat flux ( $\mathrm{W} \mathrm{m}^{-2}$ ) during $72 \mathrm{~h}$ among the nine NCM predictions (contours) and of its standard deviation (shading). Latent heat flux values instantaneously calculated every hour were used. Hai-tang's best track is also shown.

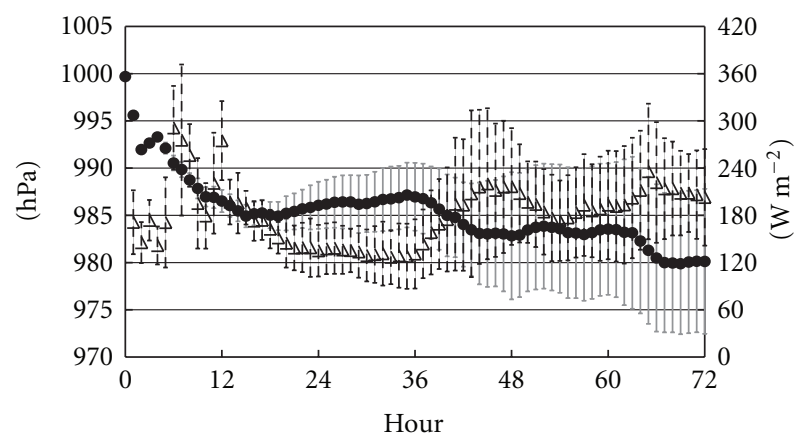

- Mean CP

$\triangle$ Mean latent

Figure 9: Time series of mean central pressure (CP, left axis) and mean latent heat flux $\left(\mathrm{W} \mathrm{m}^{-2}\right.$, right axis) and their standard deviations.

owing to the relatively weak intensity of Hai-Tang, but the standard deviation was relatively high at around $25^{\circ} \mathrm{N}$, $148^{\circ} \mathrm{E}$ because of the uncertainty of Hai-Tang's predicted central position. The standard deviation became small as integration progressed, whereas the mean latent heat flux became high as Hai-Tang intensified. Figure 9 depicts time series of mean central pressure and mean latent heat flux and their standard deviations, with mean latent heat flux calculated as the average in a $1^{\circ}$ grid box at Hai-Tang's center. The two trends are negatively correlated, similar to the trends of mean central pressure and mean MLHP (Figure 5), implying that the variation in latent heat flux is closely related to that in MLHP, although surface wind velocity is another important metric for estimating latent heat flux when Kondo's [15] bulk formulas are used.

Next, we investigated the effect of variations in oceanic preexisting conditions on the horizontal distribution of mean latent heat flux at $72 \mathrm{~h}$, averaged over the nine NCM and NHM predictions. The NCM result shows a wave-1 asymmetric distribution pattern of mean latent heat flux
(Figure 10(a)), whereas NHM produced an axisymmetric distribution pattern (Figure 10(c)). The area of high mean latent heat flux west of the mean center position of predicted Hai-Tang corresponds to Hai-Tang's mean direction of travel as predicted by NCM (Figure 2). The standard deviation of the latent heat flux predictions by NCM was high inside HaiTang's eyewall, where the horizontal gradient of surface wind velocity was variable ahead of Hai-Tang's direction of travel (Figure 10(b)), whereas the standard deviation of the NHM predictions was high behind Hai-Tang's direction of travel (Figure 10(d)). The difference in the horizontal distributions of mean latent heat flux between NCM (Figure 10(a)) and NHM (Figure 10(c)) resulted from SSC. In fact, mean latent heat flux was remarkably reduced behind Hai-Tang in NCM (Figure 10(a)) where atmospheric conditions had stabilized (not shown). High latent heat flux can be attributed to both the high-velocity surface winds associated with HaiTang's intensification (Figure 9) and high SST or mixedlayer temperature associated with high MLHP (Figure 5). This result suggests that not atmospheric thermostatics but atmospheric dynamics and oceanic preexisting conditions determined the distribution and amplitude of latent heat flux around Hai-Tang.

We then examined the horizontal distributions of mean hourly precipitation averaged over $72 \mathrm{~h}$ among the nine NCM experiments and of the standard deviation (Figure 11). Heavy precipitation was concentrated along Hai-Tang's predicted track. High mean precipitation and larger standard deviations tended to be on the south side of Hai-Tang's track. Thus, precipitation was high on the opposite side of HaiTang's track to high MLHP standard deviations (Figure 6). Figure 12 depicts time series of mean central pressure and mean precipitation and their standard deviations. Mean precipitation was calculated as the average in a $1^{\circ}$ grid box at Hai-Tang's center. Mean precipitation tended to increase as Hai-Tang intensified. We can infer that high MLHP led to increases in latent heat flux (Figures 5 and 9), which caused the enhanced release of latent in the troposphere and heavy precipitation (Figure 12). The impact of the variations in oceanic preexisting conditions on MLHP predicted by NCM can be widely seen not only around $15^{\circ} \mathrm{N}, 138^{\circ} \mathrm{E}$ and $15^{\circ} \mathrm{N}$, $150^{\circ} \mathrm{E}$ but also around the area where MLHP decreased as a result of the SSC induced by Hai-Tang (Figure 6), whereas their impact on precipitation was mainly limited to the south side of Hai-Tang.

The horizontal distribution of mean precipitation at $72 \mathrm{~h}$ (Figure 13(a)) successfully captures its wave- 1 asymmetric pattern, which is similar to the precipitation pattern observed by satellite (Figure 14). In contrast, the axisymmetric pattern near Hai-Tang's center (Figure 14) is similar to the horizontal distribution of mean precipitation at $72 \mathrm{~h}$ predicted by NHM (Figure 13(c)). The heavy precipitation near Hai-Tang's center (Figure 14) is not reproduced well (Figure 13(a)) owing to the weak intensity of Hai-Tang predicted by NCM (Figure 3(a)), but it is reproduced to some extent in the NHM prediction (Figure 13(c)). The standard deviation of predicted mean precipitation was high in both NCM (Figure 13(b)) and NHM (Figure 13(d)) where mean precipitation was also high. The impact of variations in 


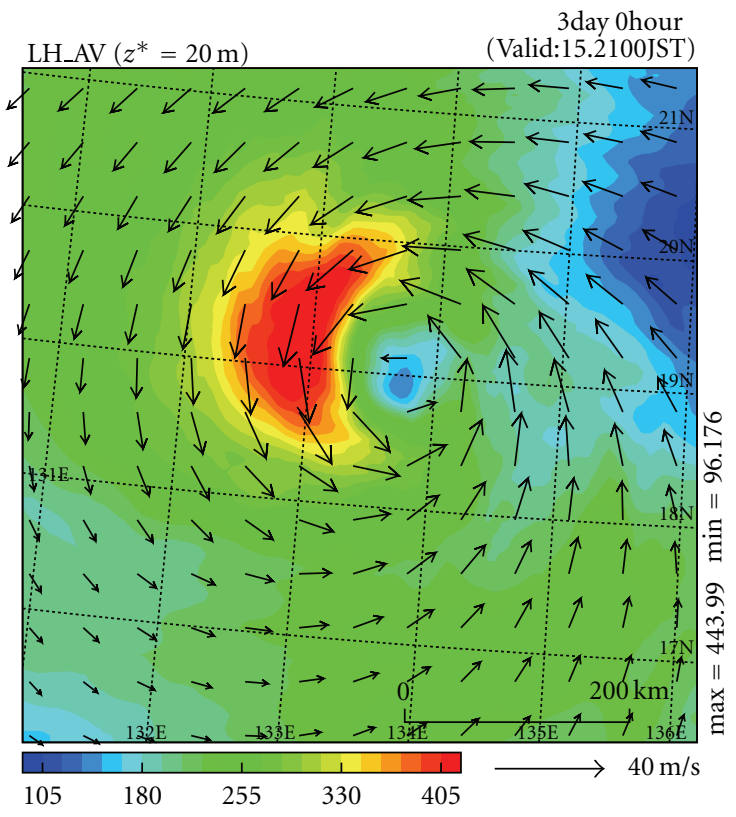

(a)

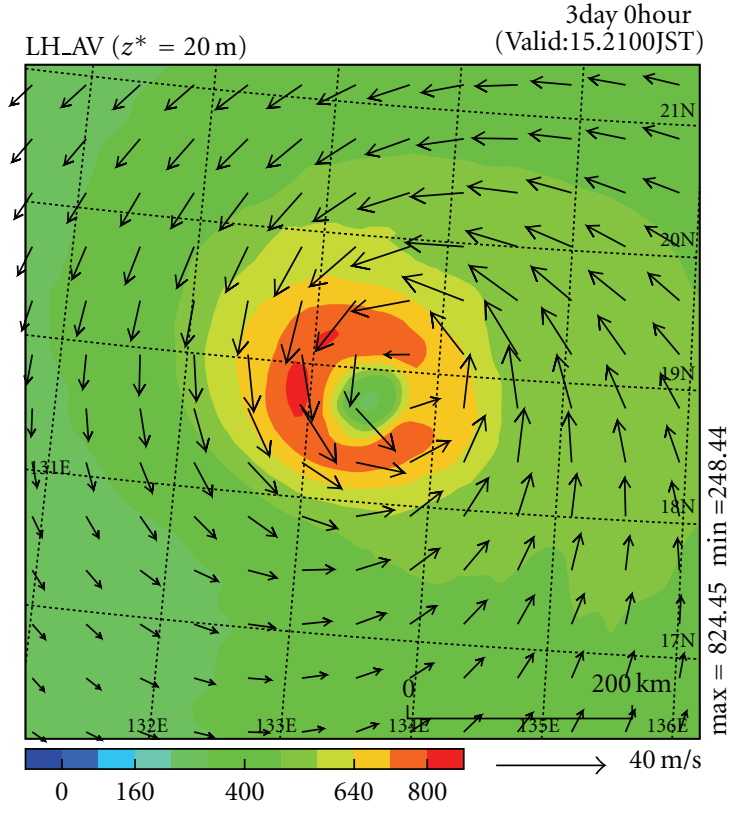

(c)

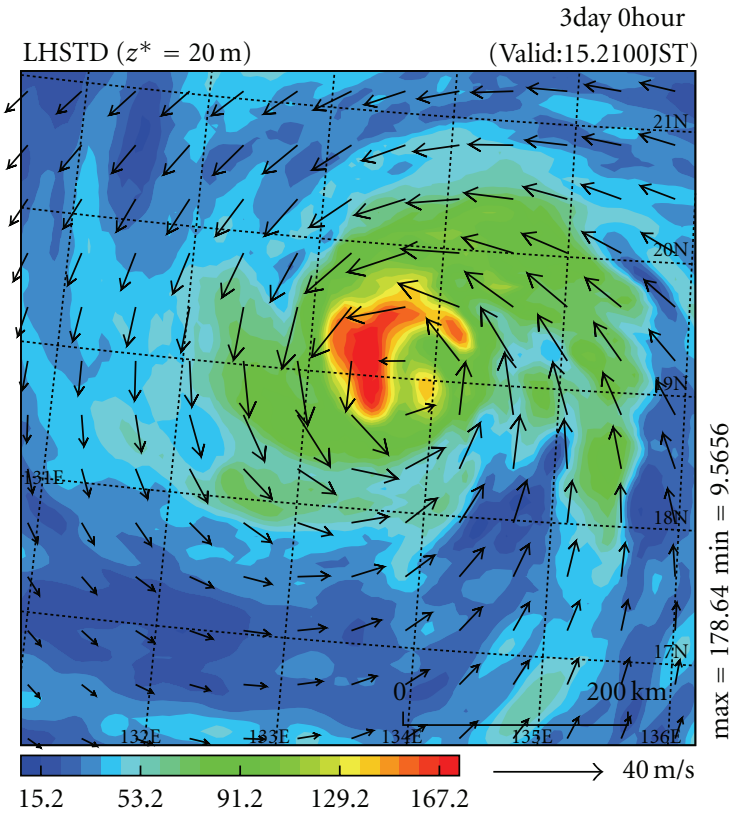

(b)

3 day 0 hour $\operatorname{LHSTD}\left(z^{*}=20 \mathrm{~m}\right) \quad$ (Valid: 15. 2100JST)

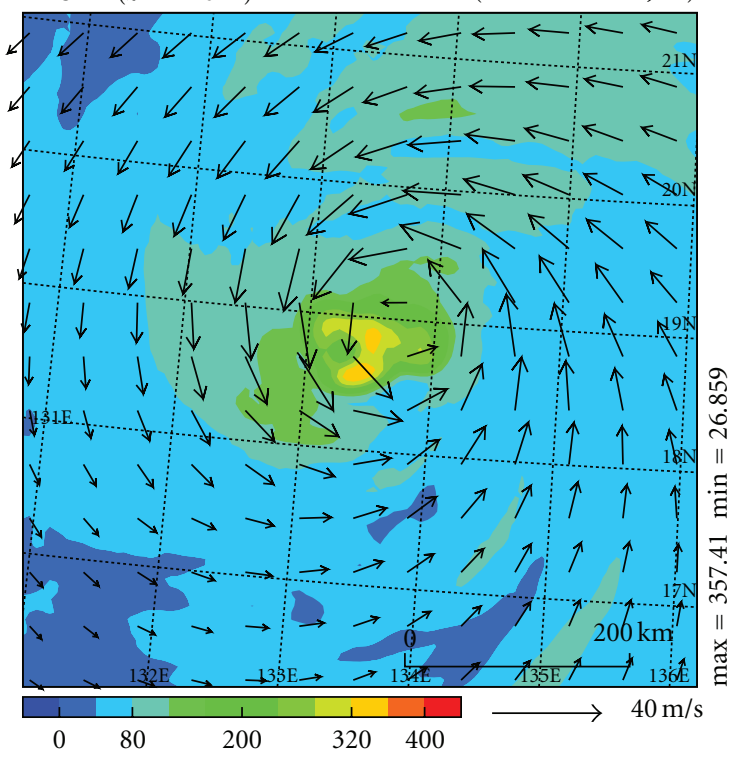

(d)

FIGURe 10: (a) Horizontal distribution of mean latent heat flux $\left(\mathrm{W} \mathrm{m}^{-2}\right)$ at $72 \mathrm{~h}$ averaged over the nine NCM predictions and (b) that of the standard deviation at $72 \mathrm{~h}$ in NCM; (c) and (d) are the same as (a) and (b), respectively, except that they show the NHM results. Mean horizontal wind field vectors at $72 \mathrm{~h}$ averaged over the nine NCM (in parts (a) and (b)) and NHM (in parts (c) and (d)) predictions are also shown in each panel.

oceanic preexisting conditions on precipitation was significant around the spiral rainband southeastward of Hai-Tang's center. In contrast, the axisymmetric pattern of precipitation vanished as a result of SSC (Figure 13(a)), suggesting that the variation in oceanic preexisting conditions directly affected the intensity of precipitation over the spiral rainbands, and then the variation over the spiral rainbands affected in turn the intensity prediction. Although Wada [8] studied intensification caused by mesovortices on spiral bands, this study demonstrated for the first time that the intensification process is influenced by variations in oceanic preexisting conditions.

To investigate the impact of variations in oceanic preexisting conditions on precipitation and Hai-Tang's intensification, we focused on the variations in mean specific humidity averaged from the surface to nearly $14 \mathrm{~km}$ height 


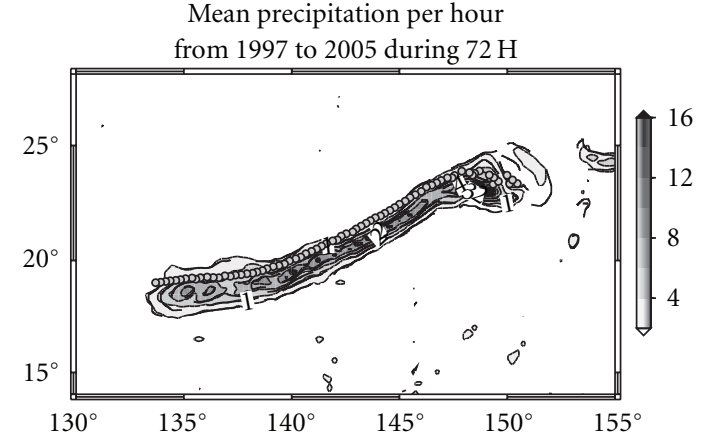

FIgURE 11: Horizontal distributions of mean hourly precipitation (mm) during $72 \mathrm{~h}$ among the nine NCM predictions (contours) and of the standard deviation (shading). Cumulative hourly precipitation was used to calculate the mean value.

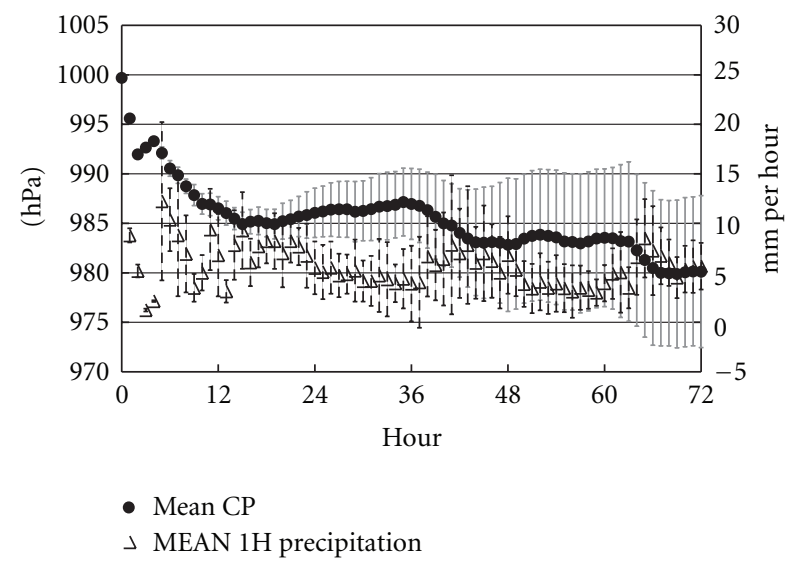

Figure 12: Time series of mean central pressure (CP, left axis) and mean hourly precipitation ( $\mathrm{mm}$, right axis) and their standard deviations.

(Figure 15(a)), mean specific cloud plus specific rain averaged from the surface to nearly $6.5 \mathrm{~km}$ height (Figure 15(b)), and the mean hourly change in potential temperature caused by radiation averaged from nearly $6.5 \mathrm{~km}$ height to $14 \mathrm{~km}$ height (Figure 15(c)). These mean values were also averaged within a radius of $300 \mathrm{~km}$ from Hai-Tang's predicted center and also over the nine NCM predictions. Figure 15 also depicts the variations in mean specific humidity, mean specific cloud plus specific rain, and mean hourly change in potential temperature caused by radiation in 1999, 2004, and 2005. Here, we consider specific humidity to represent the water vapor content, and specific cloud plus rain to represent the liquid water content.

Variations in oceanic preexisting conditions began to cause significant variation in the water vapor content around predicted Hai-Tang at $12 \mathrm{~h}$. The standard deviation increased during the early integration and reached a maximum at around $30 \mathrm{~h}$. After $36 \mathrm{~h}$, the standard deviation of the liquid water content around predicted Hai-Tang increased rapidly. Both water vapor and liquid water contents increased around predicted Hai-Tang as the predicted Hai-Tang intensified, suggesting that they can be regarded as the energy source for TC intensification. The impact of variations in oceanic preexisting conditions on the hourly change in potential temperature caused by radiation became significant after $36 \mathrm{~h}$ (Figure 15(c)), corresponding in timing to Hai-Tang's intensification, as a result of variations in Hai-Tang's atmospheric warm-core temperature caused by latent heat release. The difference in predicted central pressures among the nine NCM predictions became large at $24 \mathrm{~h}$ (Figure 3(a)) when the difference in hourly change in potential temperature caused by radiation began to appear significantly (Figure 15(c)). Predicted central pressure tended to be lower when the amplitude of diurnal variations in the hourly change in potential temperature caused by radiation was larger. The relationship was particularly marked when the oceanic preexisting conditions in 1999 were used as the initial oceanic conditions in NCM (NC99 in Table 1).

In contrast, water vapor content was markedly lower when oceanic preexisting conditions in 2004 were used as the initial oceanic conditions in NCM (NC04 in Table 1) compared with when the preexisting conditions of other years were used (Figure 15(a)). AMLHP predicted by NCM was lower in 2004 than that in any other year except 2005 (Figure 7). Liquid water content was also low at around $30 \mathrm{~h}$ and from 45 to $54 \mathrm{~h}$ in NC04 (Figure 15(b)). Lower water vapor and liquid water contents were associated with less variation in the hourly change in potential temperature caused by radiation. Thus, Hai-Tang's central pressures predicted by NHM and NCM were particularly high when the oceanic preexisting conditions in 2004 were used as the initial oceanic conditions in the models. Therefore, the oceanic preexisting conditions associated with high MLHP around Hai-Tang's track were more favorable for Hai-Tang's intensification, because both MLHP and Hai-Tang's surface winds played a crucial role in enhancing water vapor and liquid water contents around Hai-Tang as well as latent heat release in the upper troposphere, which resulted in high value of the hourly change in potential temperature caused by radiation.

\section{Discussion}

4.1. The Effect of Cumulus Parameterization. We clarified the uncertainty in TC intensity predictions caused by variations in oceanic preexisting conditions for Typhoon Hai-Tang (2005). We first demonstrated that Hai-Tang's predicted intensity was closely related to the variation in MLHP. Warm-core eddies and the climatologically deep mixed layer in the WNP played a crucial role in the intensification of Hai-Tang. We next demonstrated that water vapor and liquid water contents around Hai-Tang's center increased when predicted Hai-Tang intensified over high MLHP areas, indicating a close relationship between MLHP and water vapor and liquid water contents. However, the Kain-Fritsch cumulus parameterization scheme [14] incorporated into the NHM and NCM might have contributed to these results, even though similar results were obtained by experiments with NHM and NCM when the Kain-Fritsch's cumulus parameterization scheme was not used (not shown). HaiTang's central pressures predicted by the NHM and NCM 


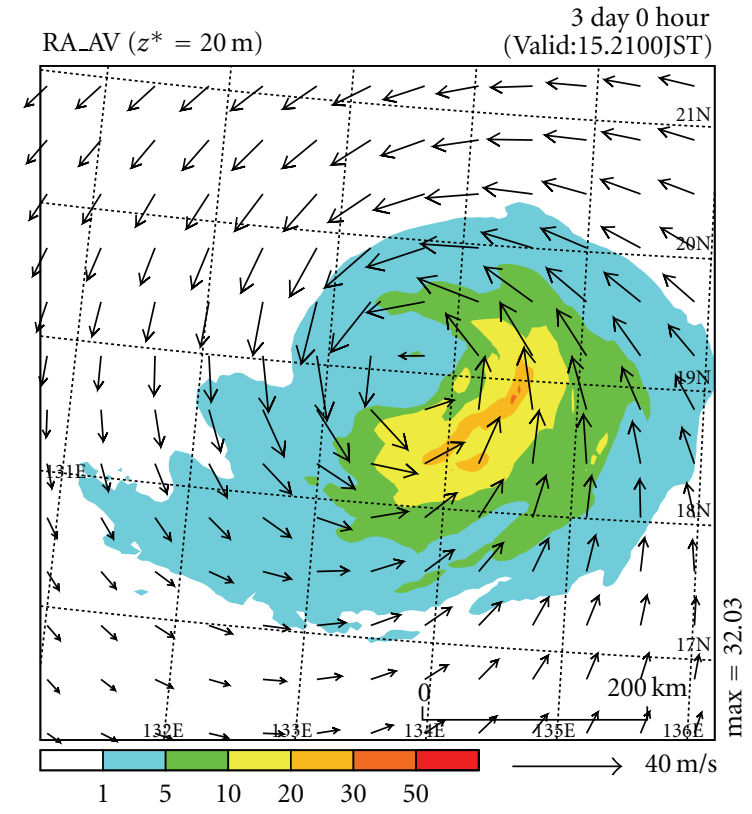

(a)

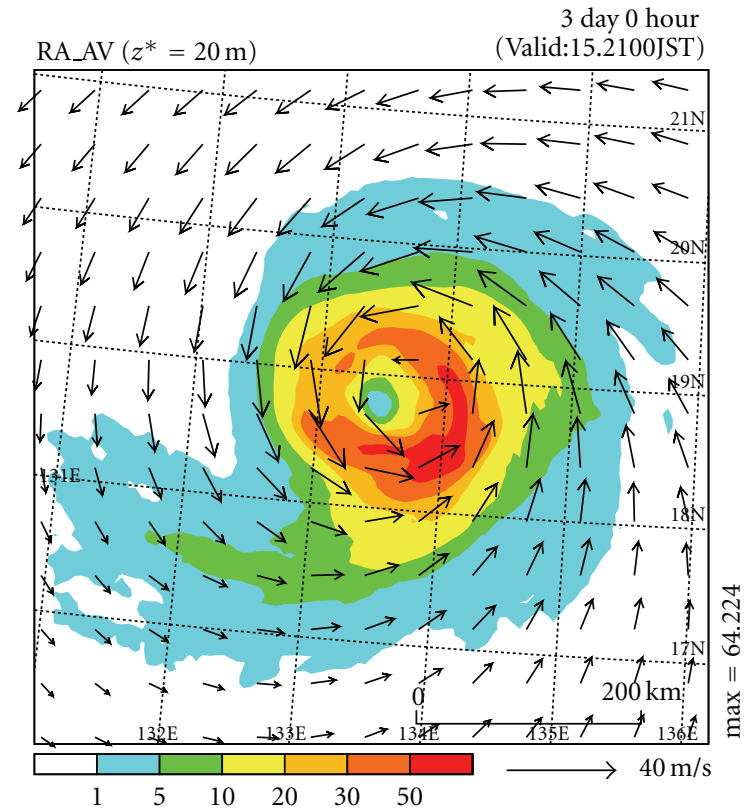

(c)

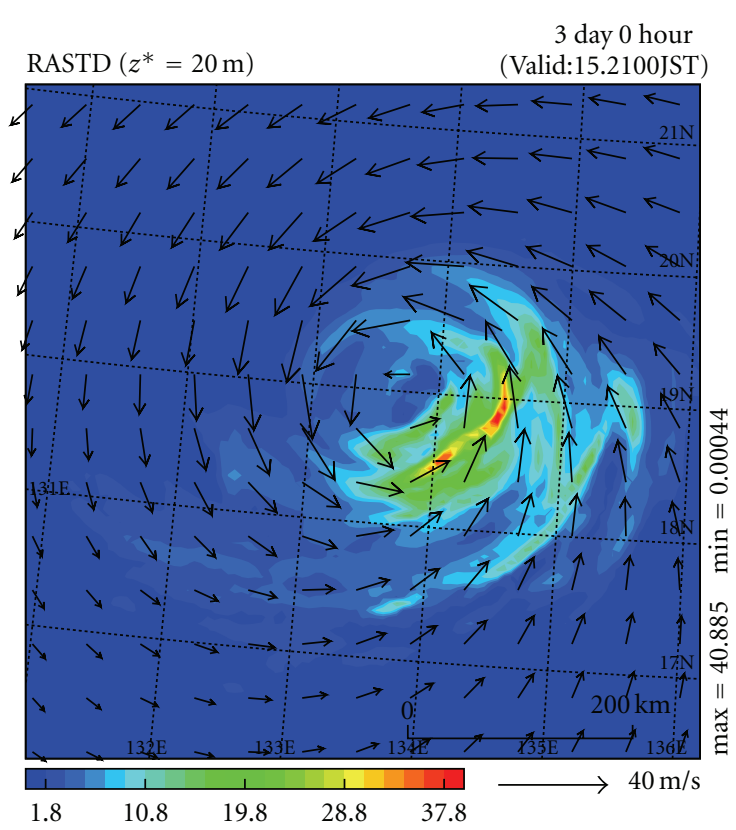

(b)

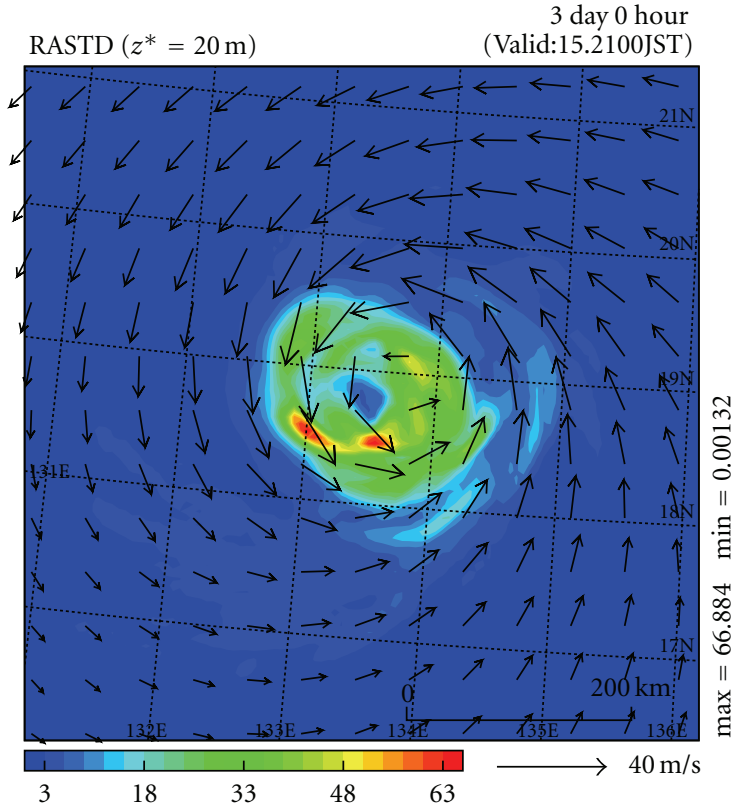

(d)

FIGURE 13: Horizontal distribution of mean hourly precipitation ( $\mathrm{mm}$ per hour) at $72 \mathrm{~h}$ averaged over the nine NCM predictions and (b) that of the standard deviation at $72 \mathrm{~h}$; (c) and (d) are the same as (a) and (b), respectively, except that they show the NHM results. Mean horizontal wind field vectors at $72 \mathrm{~h}$ averaged over the nine NCM (in parts (a) and (b)) and NHM (in parts (c) and (d)) predictions are also shown in each panel.

without using the Kain-Fritsch's cumulus parameterization scheme were higher at the $6-\mathrm{km}$ horizontal resolution than those predicted with the use of the Kain-Fritsch scheme (not shown) and far from the best-track central pressures. Therefore, in the present study we concluded that cumulus parameterization is required even at the $6-\mathrm{km}$ resolution to reproduce Hai-Tang's intensity realistically. In fact, the Kain-Fritsch's cumulus parameterization scheme is closely associated with the local Convective Available Potential Energy (CAPE). CAPE is sensitive to the local thermostatic profile in the atmospheric boundary layer, enthalpy flux, and thus SST. Thus, cumulus convection as calculated by Kain-Fritsch's cumulus parameterization is sensitive to SST. This implies that the Kain-Fritsch's cumulus parameterization possibly changes not only central pressure predictions but also the distribution patterns of latent heat flux and 


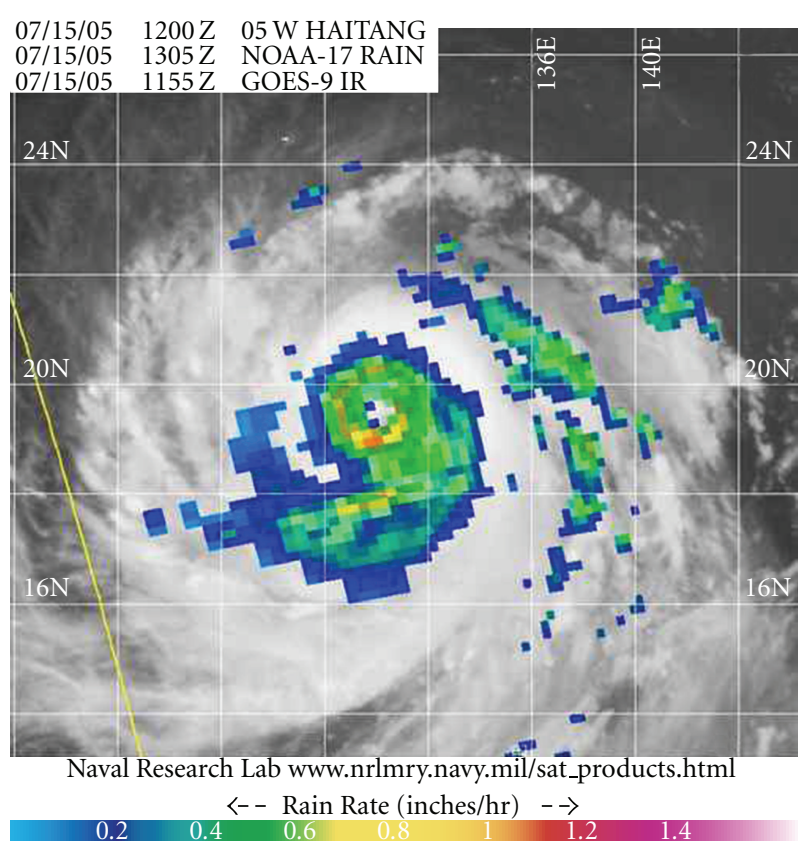

Figure 14: Advanced Microwave Sounding Unit-B (AMSUB)sensor observed rain at 1305 UTC on 15 July 2005 (color shading) superimposed on the GOES-9 IR image obtained at 1155 UTC on 15 July 2005 (gray shading) (from http://www.nrlmry.navy.mil/tc pages/tc_home.html).

precipitation intensity at around Hai-Tang's predicted center. This study does not explore the sensitivity any further.

The impact in variations in oceanic preexisting conditions on precipitation intensities on the spiral rainbands of the typhoon (Figure 13) is qualitatively consistent with the results of cloud-resolving numerical experiments [8] that SSC suppresses mesovortices along the spiral bands. This suggests that precipitation intensities on the spiral rainbands around Hai-Tang are sensitive to variations in oceanic preexisting conditions. However, the impact of oceanic preexisting conditions on precipitation intensities on the spiral rainbands still requires quantitative evaluation because of the uncertainties associated with the cumulus parameterization. To explore the relationships among MLHP, water vapor plus liquid water contents, and Hai-Tang's intensity, another numerical-prediction experiment with a grid spacing of 1 to $2 \mathrm{~km}$, should be performed with a coupled atmosphereocean model that does not include cumulus parameterization. Although such experiments would improve TC intensity prediction, many computational resources would be needed to carry them out.

The evolution of SST, and SSC in particular, was associated with the variations in oceanic preexisting conditions [1] as well as with Hai-Tang's intensity and translation [2]. The magnitude of SSC in this study tended to be larger than that obtained in the previous study [1], partly because of the northwestward track error. In addition, we must pay attention to the possibility that the tuning parameter associated with breaking surface waves in the mixed-layer formulation $[2,8]$ may be too high. High tuning parameter values lead to excessive vertical turbulent mixing near the surface because of breaking surface waves, which enhances SSC [2]. We thus need to improve the tuning parameter associated with breaking surface waves in the entrainment formulation [2] using the result of a coupled atmospherewave-ocean model.

The results of the numerical experiments of this study include the impact of diurnally varying SST in the upperocean skin layer on TC intensity prediction, but we could not separate the impact of sea-surface skin temperature variations on TC intensity prediction from that of oceanic preexisting conditions. Another numerical-prediction experiment without the upper-ocean skin-temperature scheme is needed to determine the separate impact of diurnally varying SST in the upper-ocean skin layer on TC intensity prediction. Previous study recently reported that sea-surface skin temperature variations may affect maximum hourly precipitation over the western Pacific in boreal summer and in the seasonal climatology [21]. However, the impact of diurnally varying SST on TC intensity prediction on a weather-forecasting time scale is not well understood. Moreover, the sensitivity of diurnally varying SST to oceanic preexisting conditions and to cumulus parameterization should be considered. Determination of whether oceanic preexisting conditions or sea-surface skin temperature variations significantly affect TC intensity prediction on a weather-forecasting time scale is, however, beyond the scope of this study.

4.2. Upper-Ocean Variability on Seasonal to Climate Scales. Here, we discuss the relationship between TC intensity prediction on a weather-forecasting time scale and upperocean variability on seasonal to climate time scales. Even though the time scales are different, initial oceanic conditions for predicting Hai-Tang can indeed be determined by analysis of the oceanic field, including oceanic variations on both weather-forecasting and seasonal to climate time scales. Wada and Chan [7] investigate upper-ocean variability in the North Pacific on seasonal to climate time scales in the North Pacific by using monthly oceanic reanalysis data sets calculated by MOVE. Table 3 lists the correlation coefficients between the nine NHM and NCM predicted central pressures at $72 \mathrm{~h}$ and the normalized amplitudes in July from 1997 to 2005. Wada and Chan [7] already derived the normalized amplitudes by Empirical Orthogonal Function analysis (EOF) of the 44-year monthly North Pacific TCHP data set. The central pressures predicted by the NCM at $72 \mathrm{~h}$ were significantly correlated with the normalized amplitudes of EOF first mode (EOF1) at a 90\% significance level (Table 3), indicating a significant relationship between predicted central pressures at $72 \mathrm{~h}$ around $19^{\circ} \mathrm{N}, 134^{\circ} \mathrm{E}$, and ENSO events [7]. In contrast, central pressures predicted by the NHM were significantly correlated with the normalized amplitudes of EOF second mode (EOF2) at the $80 \%$ significance level. In fact, the region with remarkable SSC around Hai-Tang's predicted track corresponds to that where TCHP remained high. The high TCHP is associated with ENSO Modoki event, when all of the North Pacific except its eastern tropical part was 


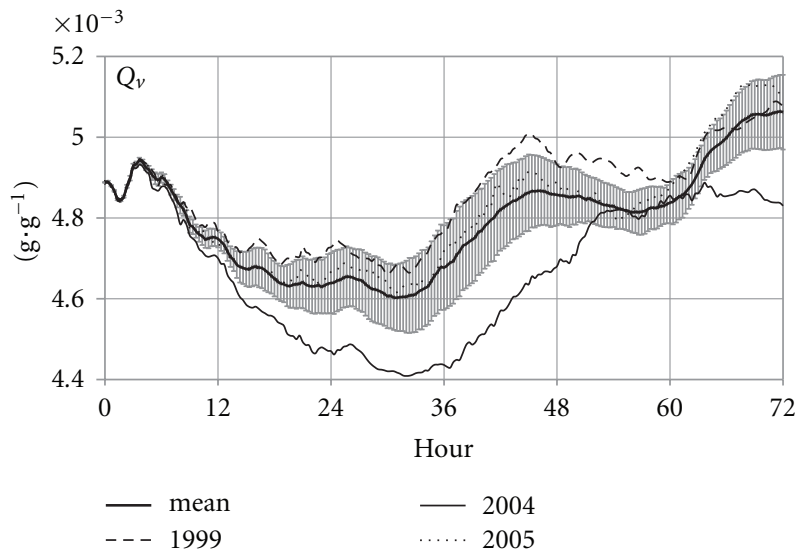

(a)

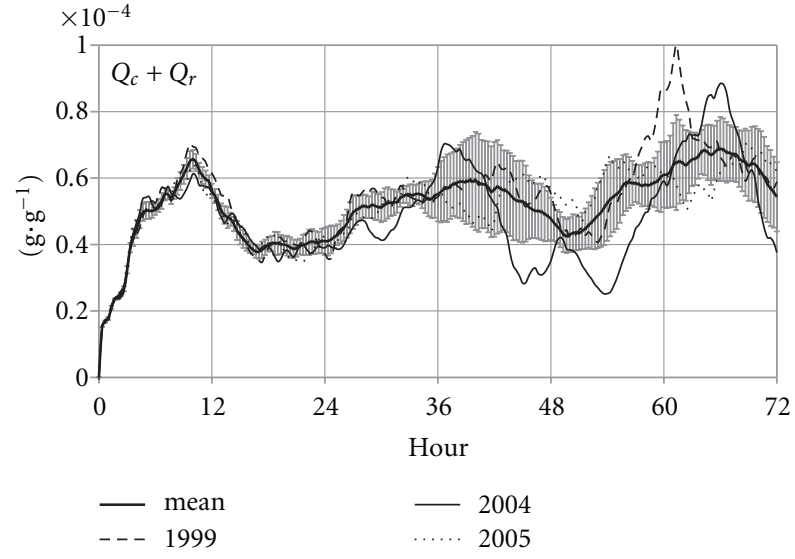

(b)

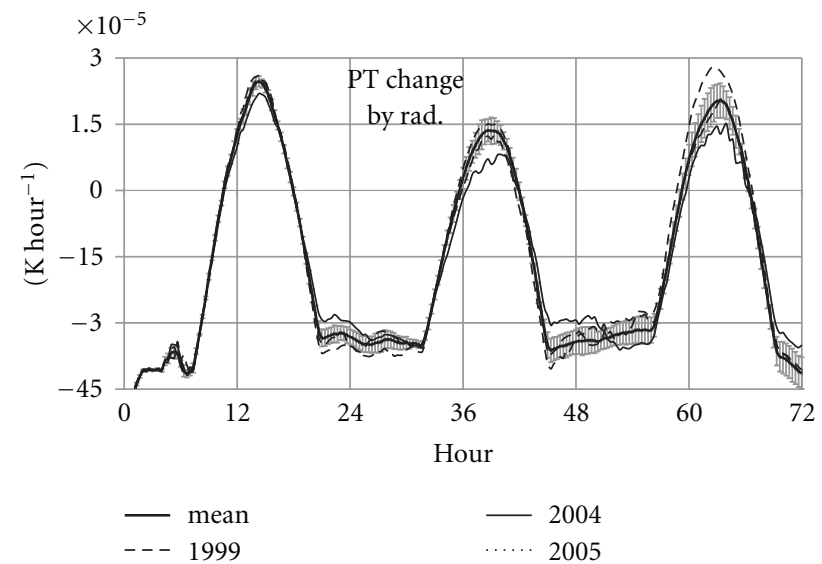

(c)

FIGURE 15: (a) Time series of mean specific humidity $\left(Q_{v}, \mathrm{~g} \cdot \mathrm{g}^{-1}\right)$ averaged over the nine NCM predictions within a radius of $300 \mathrm{~km}$ from the predicted Hai-Tang's center, along with time series of specific humidity in 1999, 2004, and 2005 predicted by NCM, also averaged within a radius of $300 \mathrm{~km}$ from the predicted Hai-Tang's center: (b) same as Figure 15(a) except for mean specific cloud $\left(Q_{c}\right)$ plus specific rain $\left(Q_{r}\right.$, $\mathrm{g} \cdot \mathrm{g}^{-1}$ ); and (c) same as Figure 15(a) except for mean hourly change in potential temperature caused by radiation (K per hour).

TABLE 3: Correlation coefficients between predicted central pressures and normalized EOF amplitudes (calculated by Wada and Chan [7]).

\begin{tabular}{lccc}
\hline Experiment & EOF1(ENSO) & EOF2(ENSO MODOKI) & EOF3 \\
\hline NHM & 0.27 & $-0.60^{* *}$ & 0.39 \\
NCM & $0.61^{*}$ & 0.00 & 0.38 \\
\hline
\end{tabular}

Significance levels: ${ }^{*} \alpha=0.1,{ }^{*} \alpha=0.2$.

relatively warm [7]. In contrast, the region with remarkable SSC corresponds to that where TCHP decreased owing to the passage of the TC during El Niño. Conversely, predicted central pressure was lowest in 1999 during the transition to a mature La Niña event, implying that a climatologically deep mixed layer in the WNP during La Niña events may cause TCs to intensify.

Chia and Ropelewski [22] reported that the climatological mean location of TC formation varies in relation to ENSO. In that sense, certain oceanic preexisting conditions matched the certain atmospheric conditions to produce reasonable atmospheric and oceanic environmental fields, which are necessary for tropical cyclogenesis and intensification in the case of super-typhoon Hai-Tang. In other words, the atmospheric thermodynamics conditions favorable to tropical cyclogenesis and intensification are associated with the oceanic preexisting conditions. Here we take as an example a typhoon generated in July 2004 in the area where Hai-Tang was generated and intensified in 2005. A tropical storm was generated at around $19.1^{\circ} \mathrm{N}, 136.3^{\circ} \mathrm{E}$ at 0600 UTC on 11 July 2004, and it became a tropical cyclone, named Typhoon Kompasu, at 0000 UTC on 14 July 2004 in a location near Hai-Tang's track. The minimum central pressure of Kompasu was $992 \mathrm{hPa}$. Thus, Kompasu did not show remarkable intensification in 2004 even though in 2005 Hai-Tang was generated and intensified in the same location. Oceanic preexisting conditions in 2004 led to the weak intensity of Kompasu, consistent with the weak intensity of predicted Hai-Tang under the initial oceanic conditions of 12 July 2004 (Figures 3(a) and 3(b)). Thus, certain large-scale atmospheric forcing must accompany the certain oceanic preexisting conditions to cause the tropical 
cyclogenesis and intensification of a super-typhoon such as Hai-Tang.

\section{Conclusion}

We qualitatively evaluated the impact of variations in oceanic preexisting conditions on predictions of Typhoon Hai-Tang in 2005 by a coupled atmosphere-ocean model to which we provided nine initial oceanic conditions obtained from daily oceanic reanalysis data for 12 July from 1997 to 2005. Our conclusions are as follows.

(1) The amplitude of the impact of the variations in oceanic preexisting conditions on predicted HaiTang's central pressure was nearly $18 \mathrm{hPa}$ at $72 \mathrm{~h}$, compared with a predicted central pressure difference of about $40 \mathrm{hPa}$ at $72 \mathrm{~h}$, predicted from the difference in sea-surface temperature (SST) between the nonhydrostatic atmospheric model (NHM) and the nonhydrostatic atmosphere model coupled with the ocean model (NCM). The marked difference between the predicted SST and the initial SST is the seasurface cooling (SSC) caused by the passage of HaiTang. The impact of SSC was more remarkable than that of variations in oceanic preexisting conditions on Hai-Tang's intensity prediction. However, to evaluate the impact of the variation in oceanic preexisting conditions on predicted Hai-Tang's central pressure quantitatively, the effect of cumulus parameterization should be considered. Numerical-prediction experiments with NCM at horizontal resolutions of $1-2 \mathrm{~km}$ will be needed in the future because of the poor intensity prediction by even the NHM at the $6-\mathrm{km}$ horizontal resolution.

(2) Warm-core oceanic eddies and a climatologically deep mixed layer led to a high mixed-layer heat potential, which increased the latent heat flux and enhanced the water vapor and liquid water contents, leading to increases in Hai-Tang's atmospheric warmcore temperature owing to latent heat release and thus intensification of Hai-Tang. The difference in the intensity predictions of Hai-Tang among the nine NCM predictions accompanied that in the hourly changes in potential temperature caused by radiation. Variations in oceanic preexisting conditions were sensitive to precipitation intensities along the spiral rainbands and thus affected Hai-Tang's intensity, whereas SSC negatively affected the formation of an axisymmetric precipitation pattern near Hai-Tang's center.

We discussed the requirement that certain large-scale atmospheric forcing must accompany the certain oceanic preexisting conditions to cause the tropical cyclogenesis and intensification of a super-typhoon such as Hai-Tang. Chan [23] also reported that locations of TC genesis varied depending on the atmospheric dynamic forcing. However, it is not well understood how the atmospheric thermodynamic field and associated oceanic preexisting conditions affect TC intensity. In this study, we successfully evaluated uncertainties in predictions of Hai-Tang's intensity related to variations in oceanic preexisting conditions. This is the first step to understanding the impact of the atmospheric thermodynamic field and its associated oceanic preexisting conditions on TC intensity and to making TC intensity prediction more precise. To explore this further, a more sophisticated oceanic data assimilation system and coupled atmosphere(-wave)-ocean model are needed. In addition, the results of the coupled model suggest that we should consider seasonal to climate variations in oceanic conditions to improve the intensity predictions on a weather-forecasting scale.

\section{Acknowledgments}

A. Wada is grateful to Dr. Y. Kawai for developing the oceanic sublayer scheme. This work was supported by the Japan Society for the Promotion of Science (JSPS), Grant-in-Aid for Scientific Research (C) (19612005 and 22540454). The authors thank Dr. T. Kato of the Meteorological Research Institute, Japan Meteorological Agency, for the use of his plotting tools. General Mapping Tools (GMT) were also used to draw figures.

\section{References}

[1] Z.-W. Zheng, C.-R. Ho, and N.-J. Kuo, "Importance of preexisting oceanic conditions to upper ocean response induced by Super Typhoon Hai-Tang," Geophysical Research Letters, vol. 35, no. 20, Article ID L20603, 2008.

[2] A. Wada, H. Niino, and H. Nakano, "Roles of vertical turbulent mixing in the ocean response to Typhoon Rex (1998)," Journal of Oceanography, vol. 65, no. 3, pp. 373-396, 2009.

[3] A. Wada, K. Sato, N. Usui, and Y. Kawai, "Comment on "Importance of pre-existing oceanic conditions to upper ocean response induced by Super Typhoon Hai-Tang" by Z.W. Zheng, C.-R. Ho, and N.-J. Kuo," Geophysical Research Letters, vol. 36, no. 9, Article ID L09603, 2009.

[4] C.-R. Ho, Q. Zheng, Z.-W. Zheng, N.-J. Kuo, C.-K. Tai, and F.C. $\mathrm{Su}$, "Reply to comment by A. Wada et al. on "Importance of pre-existing oceanic conditions to upper ocean response induced by Super Typhoon Hai-Tang"', Geophysical Research Letters, vol. 36, no. 9, Article ID L09604, 2009.

[5] A. Wada, "Numerical problems associated with tropical cyclone intensity prediction using a sophisticated coupled typhoon-ocean model," Papers in Meteorology and Geophysics, vol. 58, pp. 103-126, 2007.

[6] A. Wada and N. Usui, "Importance of tropical cyclone heat potential for tropical cyclone intensity and intensification in the Western North Pacific," Journal of Oceanography, vol. 63, no. 3, pp. 427-447, 2007.

[7] A. Wada and J. C. L. Chan, "Relationship between typhoon activity and upper ocean heat content," Geophysical Research Letters, vol. 35, no. 17, Article ID L17603, 2008.

[8] A. Wada, "Idealized numerical experiments associated with the intensity and rapid intensification of stationary tropicalcyclone-like vortex and its relation to initial sea-surface temperature and vortex-induced sea-surface cooling," Journal 
of Geophysical Research, vol. 114, no. 18, Article ID D18111, 2009.

[9] I. Ginis, “Ocean response to tropical cyclone," in Global Perspective on Tropical Cyclones, R. L. Elsberry, Ed., pp. 198260, WMO/TD-No. 693, Geneva, Switzerland, 1995.

[10] N. Usui, S. Ishizaki, Y. Fujii, H. Tsujino, T. Yasuda, and M. Kamachi, "Meteorological Research Institute multivariate ocean variational estimation (MOVE) system: some early results," Advances in Space Research, vol. 37, no. 4, pp. 806822, 2006.

[11] K. Saito, T. Fujita, Y. Yamada et al., "The operational JMA nonhydrostatic mesoscale model," Monthly Weather Review, vol. 134, no. 4, pp. 1266-1298, 2006.

[12] A. Wada and Y. Kawai, "The development of diurnallyvarying sea-surface temperature scheme. Part I. Preliminary numerical experiments," CAS/JSC WGNE, Research Activities in Atmospheric and Ocean Modelling, vol. 39, no. 4, pp. 09070908, 2009.

[13] Y.-L. Lin, R. D. Farley, and H. D. Orville, "Bulk parameterization of the snow field in a cloud model," Journal of Climate \& Applied Meteorology, vol. 22, no. 6, pp. 1065-1092, 1983.

[14] J. S. Kain and J. M. Fritsch, "A one-dimensional entraining/detraining plume model and its application in convective parameterization," Journal of the Atmospheric Sciences, vol. 47, no. 23, pp. 2784-2802, 1990.

[15] J. Kondo, "Air-sea bulk transfer coefficients in diabatic conditions," Boundary-Layer Meteorology, vol. 9, no. 1, pp. 91-112, 1975.

[16] J. B. Klemp and R. Wilhelmson, "The simulation of threedimensional convective storm dynamics," Journal of the Atmospheric Sciences, vol. 35, pp. 1070-1096, 1978.

[17] J. W. Deardorff, "Stratocumulus-capped mixed layers derived from a three-dimensional model," Boundary-Layer Meteorology, vol. 18, no. 4, pp. 495-527, 1980.

[18] M. Sugi, K. Kuma, and K. Tada, "Description and performance of the JMA operational global spectral model (JMA-GSM88)," Geophysical Magazine, vol. 43, pp. 105-130, 1990.

[19] A. Schiller and J. S. Godfrey, "A diagnostic model of the diurnal cycle of sea surface temperature for use in coupled oceanatmosphere models," Journal of Geophysical Research, vol. 110, no. 11, Article ID C11014, 2005.

[20] J. C. Ohlmann and D. A. Siegel, "Ocean radiant heating. Part II: parameterizing solar radiation transmission through the upper ocean," Journal of Physical Oceanography, vol. 30, no. 8, pp. 1849-1865, 2000.

[21] M. A. Brunke, X. Zeng, V. Misra, and A. Beljaars, "Integration of a prognostic sea surface skin temperature scheme into weather and climate models," Journal of Geophysical Research, vol. 113, no. 21, Article ID D21117, 2008.

[22] H. H. Chia and C. F. Ropelewski, "The interannual variability in the genesis location of tropical cyclones in the northwest Pacific," Journal of Climate, vol. 15, no. 20, pp. 2934-2944, 2002.

[23] J. C. L. Chan, "Thermodynamic control on the climate of intense tropical cyclones," Proceedings of the Royal Society A, vol. 465, no. 2110, pp. 3011-3021, 2009. 

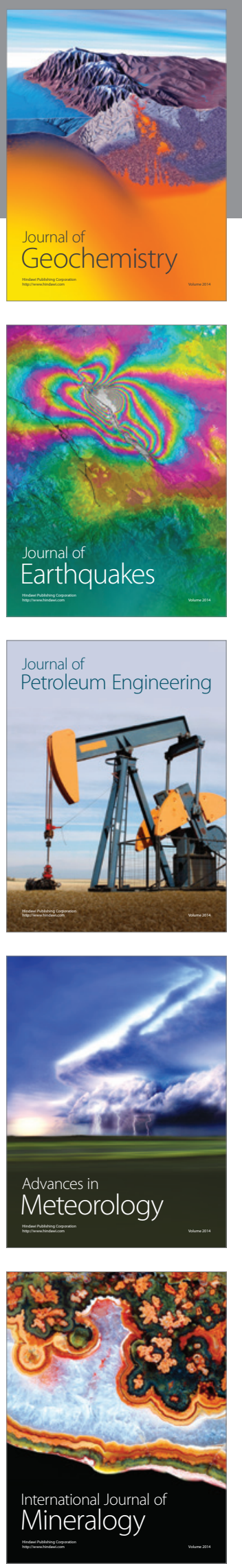
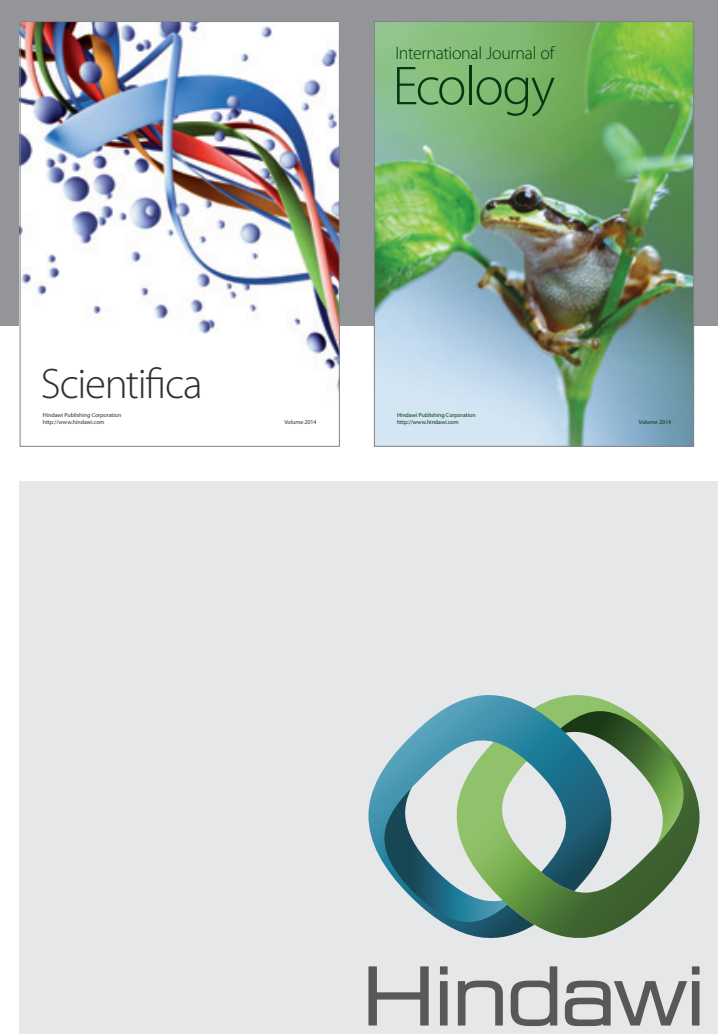

Submit your manuscripts at http://www.hindawi.com
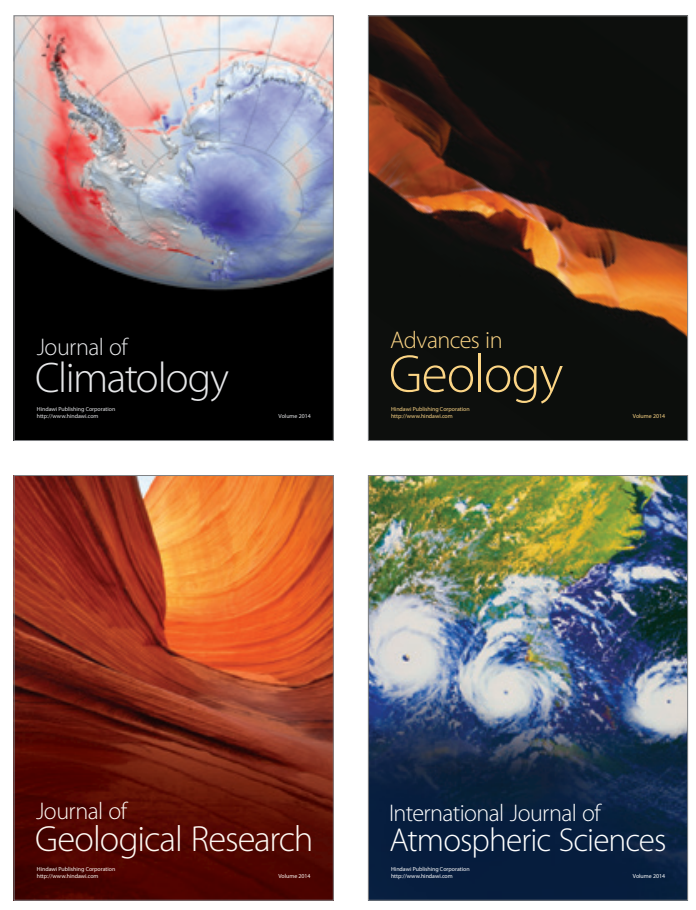
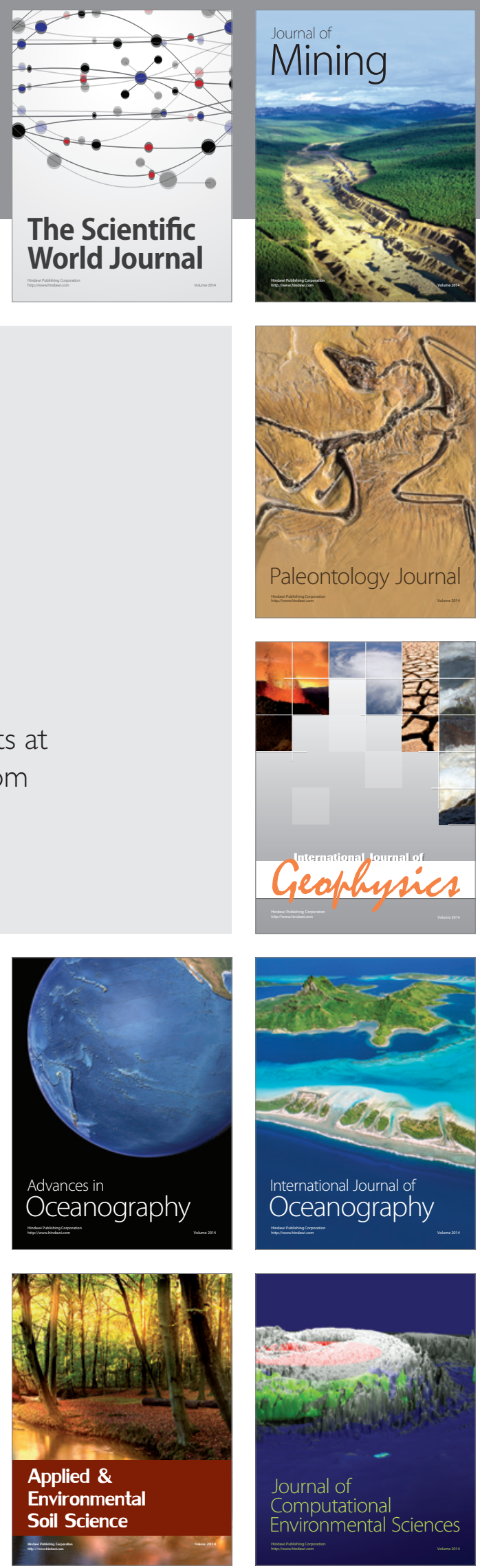